\title{
Assessing the storage potential of Australian rainforest seeds: a decision-making key to aid rapid conservation
}

\author{
K. D. Sommerville ${ }^{1}$ (D) . G. Errington ${ }^{1} \cdot$ Z-J. Newby $^{1} \cdot$ G. S. Liyanage ${ }^{1} \cdot$ C. A. Offord ${ }^{1}$
}

Received: 8 March 2021 / Revised: 13 June 2021 / Accepted: 28 June 2021 /

Published online: 19 July 2021

(c) Crown 2021

\begin{abstract}
Seed banking of rainforest species is hindered by lack of knowledge as to which species are tolerant of desiccation and freezing. We assessed 313 Australian rainforest species for seed banking suitability by comparing the germination percentage of fresh seeds to seeds dried at $15 \% \mathrm{RH}$ and seeds stored at $-20{ }^{\circ} \mathrm{C}$ after drying. We then compared desiccation responses to environmental, habit, fruit and seed characteristics to identify the most useful predictors of desiccation sensitivity. Of 162 species with $\geq 50 \%$ initial germination, $22 \%$ were sensitive to desiccation, $64 \%$ were tolerant and $10 \%$ were partially tolerant; the responses of $4 \%$ were uncertain. Of 107 desiccation tolerant species tested for response to freezing, $24 \%$ were freezing sensitive or short-lived in storage at $-20{ }^{\circ} \mathrm{C}$. Median values for fresh seed moisture content (SMC), oven dry weight (DW) and the likelihood of desiccation sensitivity $\left(P_{\mathrm{D}-\mathrm{S}}\right)$ were significantly greater for desiccation sensitive than desiccation tolerant seeds. Ninety-four to $97 \%$ of seeds with $\mathrm{SMC}<29 \%$, DW $<20 \mathrm{mg}$ or $P_{\mathrm{D}-\mathrm{S}}<0.01$ were desiccation tolerant. Ordinal logistic regression of desiccation response against environmental, habit, fruit and seed characteristics indicated that the likelihood of desiccation sensitivity was significantly increased by a tree habit, fleshy fruit, increasing fresh SMC and increasing $P_{\mathrm{D}-\mathrm{S}}$. The responses observed in this study were combined with earlier studies to develop a simple decision key to aid prediction of desiccation responses in untested rainforest species.
\end{abstract}

Keywords Desiccation sensitivity $\cdot$ Desiccation tolerance $\cdot$ Ex situ conservation $\cdot$ Freezing sensitivity $\cdot$ Seed banking $\cdot$ Seed storage behaviour

Communicated by David Hawksworth.

This article belongs to the Topical Collection: Ex-situ conservation.

K. D. Sommerville

karen.sommerville@rbgsyd.nsw.gov.au

1 The Australian PlantBank, Australian Institute of Botanical Science, Royal Botanic Gardens and Domain Trust, Mount Annan, NSW 2567, Australia 


\section{Introduction}

Rainforests are highly diverse plant communities (Corlett and Primack 2008; Sommerville et al. 2018) that provide habitat for a wide range of fauna, essential goods such as food, medicines, and clean water, and essential services such as maintenance of soil fertility, regulation of air quality and sequestration of carbon (Nahuelhual et al. 2007; Golden et al. 2012; Brandt et al. 2014; Alamgir et al. 2016; Delgado-Aguilar et al. 2017). The capacity to provide such services has been found to be greatest in areas of highest diversity (Brandt et al. 2014) yet rainforest diversity around the world continues to decline under pressure from logging and clearing for agriculture and mining (Corlett and Primack 2008; FAO 2015; Sommerville et al. 2018). Additional pressures from drought, fire, disease and climate change are driving some species towards extinction (Costion et al. 2015; Makinson 2018; Sommerville et al. 2019; Amigo 2020; Fensham et al. 2020; Halofsky et al. 2020). There is a need to act quickly to conserve rainforest diversity in ex situ collections, both to guard against the extinction of individual species and to provide a source of material for restoring rainforest habitats.

Seedbanking is the most efficient and cost-effective method for conserving seed-bearing species ex situ (Offord and Meagher 2009) and protocols for conserving seed from relatively dry habitats have been well-honed over the past few decades. Species in these habitats tend to produce seeds with characteristics essential to surviving storage in a seedbank (Tweddle et al. 2003; Wyse and Dickie 2017), i.e. tolerance of drying to low moisture content and tolerance of storage at cold temperatures (Roberts 1973). In contrast, these characteristics are considered to be lacking in the seeds of many rainforest species (VázquezYanes and Orozco-Segovia 1993). Tweddle et al. (2003), for example, found that $47 \%$ of 178 tree and shrub species from tropical-subtropical evergreen rainforest were sensitive to the drying required for seedbanking. Similar results were obtained by Hamilton et al. (2013) for Australian rainforests (43\% of 69 woody species), while Lan et al. (2014) found the proportion to be much higher in tropical rainforest in Southern China (68\% of 41 wild woody species). In contrast, herbaceous species often have desiccation tolerant seeds and recent modelling by Wyse and Dickie (2017) indicated that the proportion of species with desiccation sensitive seeds in evergreen rainforest may be as low as $18.5 \%$ when herbaceous species are included.

The expectation of high levels of desiccation sensitivity in rainforest habitats has meant that the bulk of global seed banking efforts to date have been directed toward dryland species. The Millennium Seedbank in the Royal Botanic Gardens, Kew, for example, now holds seed collections for more than 36,975 species from 189 countries and territories, the majority of which were collected from dry habitats (Liu et al. 2018). The ongoing destruction of rainforests around the globe indicate that it is essential to begin directing more effort towards seed banking species from wetter environments. This, in turn, requires a concerted effort to determine which species may be stored using conventional methods and which may not.

In 1996, Hong and Ellis published a reliable protocol for determining seed storage behaviour based on testing germination following drying to progressively lower moisture content and storage at progressively lower temperatures. Accurate determination of the response to drying and storage using this protocol demands thousands of seeds which the authors acknowledged are not always available for wild species. Several options for adapting the protocol were proposed for situations where seeds were limited; however, for rainforest species, application of even the modified protocols is complicated by the difficulty 
of collecting seeds in sufficient number for complete testing (particularly for species with very large seeds), and the great length of time it can take to complete a single germination experiment (up to 2 years, in some cases; Sommerville et al. 2018).

A protocol reducing the number of seeds required to 100 was developed by Pritchard et al. $(2004 \mathrm{a}, \mathrm{b})$. This method is useful for gaining an indication of response to desiccation to low moisture content but doesn't give an indication of whether a species might tolerate drying to a lesser extent, nor whether the desiccation tolerant species are likely to tolerate cold storage. The method is also still subject to the vagaries of seed germination, and the requirement to hold a control sample of seeds in moist storage can be difficult to meet due to the tendency of rainforest seeds to lose viability (Mattana et al. 2019), become contaminated with fungi (Baskin and Baskin 2014) or to begin germinating (Berjak and Pammenter 2008) under moist storage conditions. A surrogate method for distinguishing desiccation sensitive from desiccation tolerant species, without performing germination tests, would greatly aid the conservation of such species.

A variety of morphological and ecological differences have been observed between desiccation sensitive and desiccation tolerant seeds that might be useful in this regard. For example, $99 \%$ of seeds with physical dormancy (i.e. a water-impermeable seed coat) have been found to be tolerant of both desiccation and cold storage (Tweddle et al. 2003). The average moisture content (at maturity) and dry weight of desiccation sensitive seeds have been found to be significantly greater than that of desiccation tolerant seeds (Hong and Ellis 1996; Daws et al. 2005; Hamilton et al. 2013), while seeds with a dry weight less than $10 \mathrm{mg}$ were found, in one study, to be uniformly desiccation tolerant (Hamilton et al. 2013). The average seed coat ratio (the ratio of the mass of the dried seed coat to the whole seed) of desiccation sensitive seeds has been found to be significantly lower than desiccation tolerant seeds (Chen et al. 2020), while seeds with green embryos have generally been found to be desiccation sensitive (Hamilton et al. 2013). In terms of ecology, desiccation sensitivity has been found more frequently in species growing in moist habitats than arid habitats (Tweddle et al. 2003; Wyse and Dickie 2017) and has been found more likely to occur in seeds dispersed during the wet season than the dry season (Daws et al. 2005). All of these observations are useful to understanding seed ecology and the potential for desiccation sensitivity; however, overlap in the values of some traits, and notable exceptions in others, has limited their individual usefulness in predicting the desiccation response of untested species.

Several attempts have been made to develop models for predicting desiccation sensitivity using two or more seed traits. One method proposed by Hong and Ellis (1996) utilised dry seed weight and seed moisture content at shedding. This method accurately predicted desiccation tolerance for small seeds with relatively low moisture content, and desiccation sensitivity for large seeds with high moisture content, but could not distinguish between desiccation responses for seeds in the middle of the range for both characters. Similar results were obtained using this model by Ellis et al. (2007) and Lima et al. (2014). Daws et al. (2006) developed a model utilising dry seed weight and seed coat ratio to derive a value for the probability of desiccation sensitivity $\left(P_{\mathrm{D}-\mathrm{S}}\right)$. This method was able to predict desiccation sensitivity with $85 \%$ accuracy for seeds that met particular criteria (i.e. $P_{\text {D-s }}>0.5$; Daws et al. 2006; Lan et al. 2014). The method is useful for identifying some species that could be ruled out for standard seedbanking but does not distinguish between desiccation sensitive and desiccation tolerant seeds with $P_{\mathrm{D}-\mathrm{S}}$-values below 0.5. Pelissari et al. (2018) produced a revision of this model that incorporated the water content of the embryo and endosperm at shedding and found the model correctly classified both 
desiccation tolerance and desiccation sensitivity in 46 of 50 tropical tree species. This method seems promising but has not yet been validated for species with a non-tree habit.

Recent modelling based on storage behaviour data for a large number of species has also provided useful information on indicators of desiccation response. Wyse and Dickie (2018) analysed data for 17,539 species held in the Kew Seed Information Database and determined that the most useful predictor of desiccation tolerance for a given species was the known response of other species in the same genus. The authors also found seed mass to be a significant predictor of desiccation sensitivity; however, this factor had a relative influence of only $2.7 \%$ in the model and so may be more difficult to apply directly. The model provided a great step forward in predicting seed storage behaviour for untested species; however, the data analysed were of necessity biased towards dryland species, and there are many genera occurring in rainforest for which no species have yet been tested $(>790$ genera in the South Pacific region alone; Sommerville et al. 2018). In addition, there are some notable examples of genera which contain both desiccation sensitive and desiccation tolerant species (e.g. Acer and Araucaria; Hong and Ellis 1996). A step-by-step decisionmaking tool incorporating all of the above factors would aid the efforts of the seed banking community to conserve rainforest species from previously untested genera.

To derive some clarity from this complexity, we aimed to test the desiccation and freezing tolerance of 313 Australian plant species occurring in a variety of rainforest types. We compared desiccation responses to seed moisture content, seed weight, seed coat ratio and $P_{\mathrm{D}-\mathrm{S}}$ to see if patterns observed in previous studies applied to this set of species. We analysed desiccation response in relation to a range of environmental, fruit, and seed characteristics to identify the most useful predictors of desiccation tolerance or sensitivity. Finally, we combined the results of this study with the findings of previous authors to develop a decision-making tool to facilitate more rapid screening of rainforest species for seedbanking.

\section{Materials and methods}

\section{Collection}

Fresh fruits for the majority of species tested were collected from wild populations in littoral, subtropical, temperate or dry rainforests in New South Wales, Australia (Fig. 1). The fruits collected consisted of a mixture of fleshy indehiscent, fleshy dehiscent, dry indehiscent and dry dehiscent types (Fig. 2). Where population density allowed, mature whole fruits were sampled from multiple individuals, but collections were generally only possible from a small number of individuals. For 17 species, seeds were collected from 1 to 3 individuals cultivated at the Australian Botanic Garden, Mount Annan; ten of these species were originally sourced from a known wild provenance; Online Resource 1). Fruits were collected directly from the plant or, if inaccessible on the plant itself, freshly fallen fruits (i.e. showing no obvious signs of deterioration) were collected from the ground beneath the plant. For species with asynchronous ripening, mature individual fruits were selected from the fruit available on the day of collection. For species with fleshy fruits or suspected high seed moisture content, whole fruits were placed in plastic bags and held in a portable electric fridge at $10{ }^{\circ} \mathrm{C}$ for up to ten days during transport to the Australian PlantBank. Dry-fruited species were placed in calico bags and held at ambient temperature during 


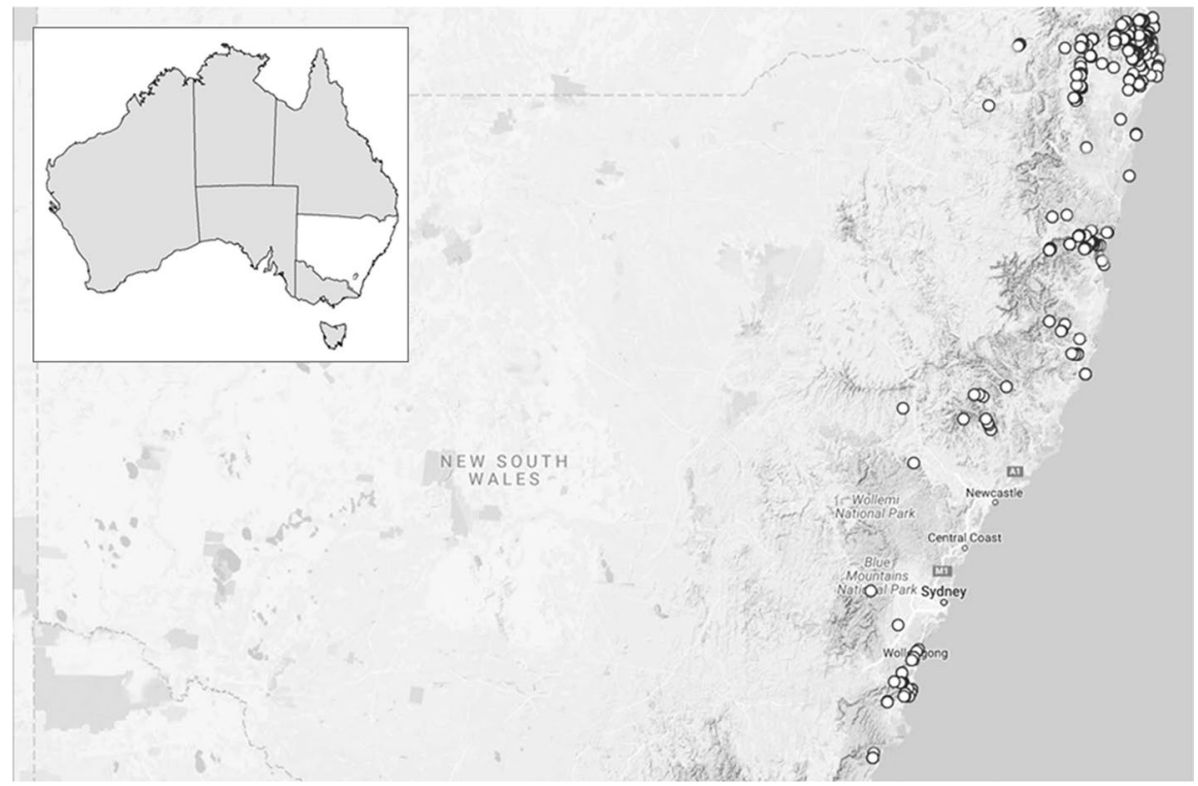

Fig. 1 Seeds assessed for desiccation sensitivity were collected from a variety of rainforest habitats on the east coast of NSW, Australia

transport. Herbarium specimens, with accompanying data on habitat and location, were collected for each species and lodged at the National Herbarium of NSW.

\section{Processing}

The processing of fleshy fruited species commenced as soon as possible after material arrived at PlantBank; however, in some cases, material was stored at $15{ }^{\circ} \mathrm{C}$ for several days before cleaning. The total period of storage from collection to initial germination testing was 14 days or less. Seeds of dry-fruited species were generally extracted by hand. Seeds of fleshy fruited species were extracted by hand or by macerating the fruit and separating seed from pulp by flotation. For species where it was difficult to separate seed from flesh (e.g. Fontainea spp), the fruits were first macerated then agitated in a solution of $10 \mathrm{ml} \mathrm{L}-1$ enzyme (Everzym Liquid, Ever SRL, Pramaggiore, Italy) for up to $48 \mathrm{~h}$ to facilitate flesh removal.

A sub-sample of fresh seeds was set aside for germination testing and determination of seed moisture content. The remainder were transferred to a drying room maintained at approximately $15{ }^{\circ} \mathrm{C}$ and $15 \%$ relative humidity (RH). Equilibration to the drying environment was determined by periodically measuring the equilibrated $\mathrm{RH}$ of a sub-sample of seeds using a Rotronic ${ }^{\circledR}$ eRH meter (Model HP23-AW-A) with a Rotronic ${ }^{\circledR}$ water activity probe (Model HC2-AW; Pryde Measurement, Ingleburn NSW). Seeds were considered dry when the RH matched that of the drying room or when there was no further change in two successive measurements. A sub-sample of dried seeds was set aside for germination testing and determination of seed moisture content. The remainder were vacuum-sealed into laminated foil bags and placed into storage at $-20{ }^{\circ} \mathrm{C}$ for at least one month before 


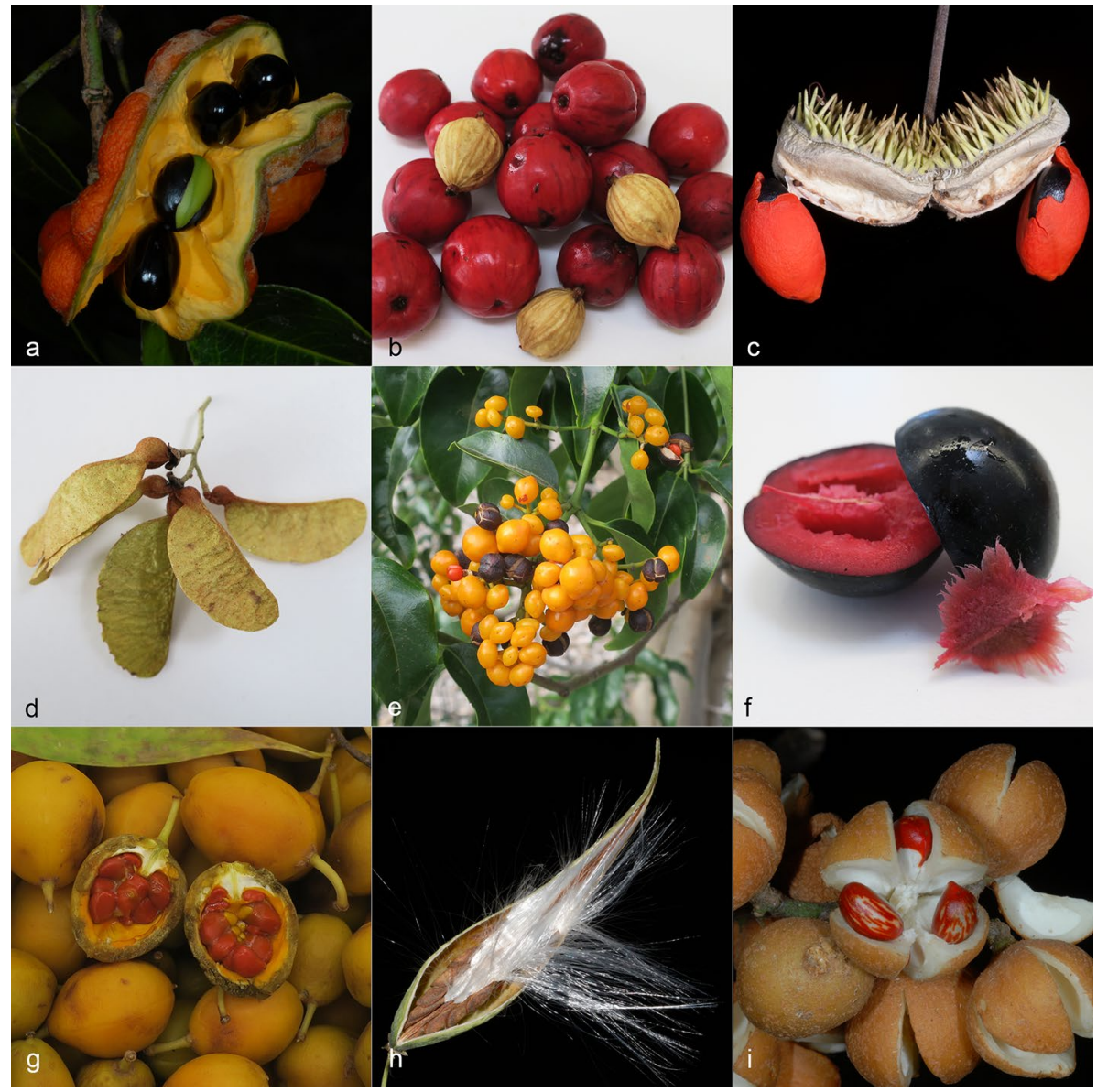

Fig. 2 A selection of the rainforest fruits collected representing fleshy and dry, dehiscent and indehiscent fruit types: a Archidendron hendersonii; b Cryptocarya laevigata; c Sloanea woollsii; d Argyrodendron trifoliolatum; e Emmenosperma alphitonioides; f Davidsonia pruriens; $\mathbf{g}$ Pittosporum angustifolium; $\mathbf{h}$ Cynanchum elegans; and i Dysoxylum fraserianum

thawing and germination testing. For some species, seed collections already stored in vacuum-sealed packets at the Australian PlantBank were used to infer tolerance of drying and freezing, without comparison to fresh seeds, if they showed a high germination percentage after freezer storage (see Online Resource 1). In those cases, seed moisture content was tested on the thawed seeds and was assumed to approximate the moisture content at the time of packaging.

\section{Determination of moisture content and dry weight}

Seed moisture content (SMC) and oven dry weight (DW) were determined for whole fresh seeds and for seeds that had equilibrated to the drying environment. To determine SMC, seeds were weighed, dried for $17.5 \pm 0.5 \mathrm{~h}$ at $103{ }^{\circ} \mathrm{C}$ (following ISTA 2007), cooled to 
room temperature over silica gel in an airtight container, then re-weighed. Seeds extracted from fleshy fruit (either by hand or using the maceration technique) were blotted dry with paper towelling prior to initial weighing.

For most species, average SMC and DW were calculated from 10 replicates of individual, randomly selected, seeds. For small-seeded species, SMC and DW were determined from 3 replicates of 5 to 100 seeds, depending on seed size. SMC was calculated as recommended by ISTA (2007).

\section{Determination of seed coat ratio and $P_{\mathrm{D}-\mathrm{s}}$}

Seed coat ratio (SCR) was determined by extracting the embryo and endosperm from ten individual seeds (for large-seeded species) or three replicates of 10 seeds (for smallerseeded species). The separated embryo/endosperm and covering structures (endocarp and testa) from each seed were dried for $17.5 \pm 0.5 \mathrm{~h}$ at $103{ }^{\circ} \mathrm{C}$, cooled to room temperature over silica gel in an airtight container, then re-weighed. SCR was calculated as the mean ratio of the weight of the dried covering structures to the weight of the whole dried seed Grubb and Burslem, 1998; Pritchard et al. 2004a, b). The likelihood of desiccation sensitivity $\left(P_{\mathrm{D}-\mathrm{S}}\right)$ was calculated using the formula proposed by Daws et al. (2006):

$$
P_{\mathrm{D}-\mathrm{S}}=\frac{e^{3.269-9.974 a+2.156 b}}{1+e^{3.269-9.974 a+2.156 b}}
$$

where $a$ is SCR and $b$ is $\log _{10}$ (seed dry weight) in $\mathrm{g}$.

\section{Germination testing}

Germination tests were attempted for a total of 313 species representing a variety of plant forms (herbs, climbers, shrubs, shrub/trees and trees) from a range of rainforest habitats. To assess the impact of storage, the germination percentage of fresh seeds was compared to that of seeds dried at $15 \% \mathrm{RH}$ and $15-20{ }^{\circ} \mathrm{C}$, and seeds stored at $-20{ }^{\circ} \mathrm{C}$ after drying. For a few species, germination following drying at higher relative humidity was also assessed. The germination conditions applied to each species (incubation temperature, substrate and pre-treatments) were selected based on those reported for previous germination tests where such information was available. This information was derived from an in-house database maintained by The Royal Botanic Gardens and Domain Trust, the online Kew Seed Information Database (Royal Botanic Gardens Kew 2020) and Floyd (2008).

In the absence of previous germination data, a substrate successfully used for germination of related species was selected and the species' distribution was used to determine the incubation temperature: species collected south of Sydney in New South Wales were germinated at $20^{\circ} \mathrm{C}$; all others were germinated at $25^{\circ} \mathrm{C}$, with the exception of 13 species germinated in a glasshouse which were subjected to variable temperatures governed by the season they were sown (Online Resource 1). A 12-h photoperiod was maintained for all laboratory experiments; the photoperiod for glasshouse experiments ranged from $10 \mathrm{~h}$ in winter to $14 \mathrm{~h}$ in summer (https://www.timeanddate.com/sun/australia/sydney, accessed 9 Dec 2020). Where possible, woody endocarps were cracked in a vice or removed entirely prior to germination testing. 
Tests conducted on agar consisted of three to five replicates of ten seeds per species. For large seeds, and those that were rapidly contaminated with fungi when sown on agar, $30-50$ seeds were sown into individual cells of a plastic germination tray containing a 1:1 mix of steam-sterilised sharp sand and perlite. The germination trays were watered to runoff at the time of sowing then covered with a plastic hood. A reservoir of water was maintained beneath each germination tray for the duration of the experiment to assist in maintaining high relative humidity.

Seeds were considered to have germinated when $2 \mathrm{~mm}$ of the radicle had emerged (for seeds sown on agar) or the hypocotyl had emerged (for seeds sown in sand-perlite mix). Observations of germination were made weekly, initially, then less frequently if germination was prolonged and sporadic. Experiments were terminated when all seeds had germinated, or when no further germination had been observed in the preceding month. Seeds sown in seed-raising mix were left indefinitely so long as they appeared viable. At the conclusion of each experiment, any seeds that failed to germinate were dissected to assess their viability; the final germination percentage was adjusted for any empty seeds identified.

For germination experiments performed using three to five replicates in Petri dishes, differences in germination among fresh, dried and freezer-stored seeds were analysed using a non-parametric one-way analysis of variance (Kruskal and Wallis 1952). For germination experiments performed by sowing seeds into individual cells of seed-raising mix, differences among treatments were analysed using a $2 \times 2$ contingency table with chi-squared statistics calculated using the ' $N$-1' method recommended by Campbell (2007).

\section{Seed storage behaviour}

Seed storage behaviour was assessed for seeds that had a fresh germination percentage of $50 \%$ or higher. In cases where fresh seed was not available, or the germination percentage was higher after drying, this criterion was applied to the germination percentage after drying. Seeds were described as 'desiccation sensitive' if the germination after drying was less than $5 \%$ and a post-germination cut test indicated any non-germinating seeds were no longer viable. Seeds were classified as 'desiccation tolerant' if germination after drying was not significantly less than germination when fresh or 'partially desiccation tolerant' if germination after drying was significantly reduced and any non-germinating seeds were no longer viable. Seeds were classified as 'freezing tolerant' if germination after freezing was not significantly different to germination after drying, and 'freezing sensitive or shortlived' if germination after freezing was significantly less than germination after drying. Based on these assessments, and the seed storage categories described by Hong and Ellis (1996) and Royal Botanic Gardens Kew (2020), seeds were categorised as 'recalcitrant or intermediate' (R/I) if sensitive to desiccation at $15 \% \mathrm{RH}$, 'intermediate' (I) if partially desiccation tolerant or freezing sensitive/short-lived, and 'probably orthodox' $\left(\mathrm{O}_{\mathrm{P}}\right)$ if found to be tolerant of both drying and freezing.

\section{Assessment of desiccation response by plant habit and habitat}

The habit of each species, and the range of habitat types occupied, were determined by reference to Harden et al. $(2006,2007)$ and the online databases 'Australian Tropical Rainforest Plants' (Zich et al. 2018) and 'PlantNET' (RBG\&DT 2020). Species were grouped into five habit categories (herb, climber, shrub, shrub/tree or tree) and four habitat categories: wet rainforest only (including tropical, subtropical, warm temperate and cool temperate 
rainforest); dry rainforest only (including dry rainforest, monsoon rainforest and vine thickets); wet and dry rainforest (including any combination of wet and dry rainforest types); and mixed habitats (including any combination of rainforest and non-rainforest habitats). Species occurring in littoral rainforest were placed in the 'wet and dry' category since that habitat has characteristics of both rainforest types (Floyd 1990; Harden et al. 2006). Differences in the proportion of desiccation sensitive species among habit and habitat categories were analysed using $2 \times 2$ contingency tables with chi-squared statistics calculated using the ' $N-1$ ' method recommended by Campbell (2007). Differences in the proportion of desiccation sensitive species among habit and habitat categories were also analysed for a larger dataset incorporating species from this study and 59 Australian rainforest species assessed by Hamilton et al. (2013).

\section{Assessment of desiccation response by seed characteristics}

Differences in fresh SMC, DW, SCR and $P_{(\mathrm{D}-\mathrm{S})}$ among species classified as desiccation tolerant, partially desiccation tolerant or desiccation sensitive were compared using a nonparametric one-way analysis of variance (Kruskal and Wallis 1952) for this dataset and for a larger Australian dataset incorporating 59 species assessed by Hamilton et al. 2013. For each variable, 'cut-off' values above or below which the majority of seeds were desiccation sensitive (or desiccation tolerant) were noted.

The Australian dataset was then combined with data on 48 species from tropical rainforest in Southern China (Lan et al. 2014) and 104 species from tropical semi-deciduous rainforest in Panama (Daws et al. 2006). Differences in fresh SMC, DW and $P_{(\mathrm{D}-\mathrm{S})}$ between desiccation sensitive and tolerant seeds were again assessed using a non-parametric oneway analysis of variance (Kruskal and Wallis 1952) and values marking a point above or below which the majority of seeds were either desiccation sensitive or tolerant were noted. The full range of values for each seed characteristic was then subdivided into 4-6 categories (each containing at least 45 species) and plotted against the relative proportions of desiccation sensitive and tolerant seeds. For this purpose, the 17 partially desiccation tolerant species from this study were included in the desiccation tolerant group on the assumption they will be storable with a slightly higher moisture content. $P_{(\mathrm{D}-\mathrm{S})}$ values were used as provided in the datasets compiled by Lan et al. (2014) and Daws et al. (2006) but were calculated from the values for seed dry weight and seed coat ratio presented in Hamilton et al. (2013).

\section{Modelling of desiccation responses}

Logistic regression was used to assess the relative influence of latitude, climatic variables, habitat, habit, and fruit and seed characteristics on the likelihood of desiccation sensitivity. Data on latitude and longitude for each collection location were obtained using a hand-held GPS unit at the time of seed collection. Data on mean annual rainfall, temperature, and maximum temperature for each collection location were derived from the ANUClimate collection datasets compiled by $\mathrm{Xu}$ et al. (2014a, b, c) and described in $\mathrm{Xu}$ and Hutchison (2010).

Ordinal logistic regression with a logit link function was first used to fit a full model (Model 1) linking the desiccation response (sensitive, partially tolerant or tolerant) of 156 species from the present study to latitude, climate (mean rainfall, temperature, and maximum temperature at the collection location), plant characteristics [habit, habitat range, fruit 
type (fleshy or dry) and fruit dehiscence type (dehiscent or indehiscent)] and DW. Predictor variables that were not associated with the outcome variable at a statistically significant level were removed from the model one by one (least significant variables first) until a reduced model was obtained where all the variables remaining were statistically significant $(P<0.05)$. Pearson and Deviance goodness-of-fit tests were applied to check the fit of the final model. A second OLR model combining significant predictors from Model 1 with fresh SMC and $P_{\mathrm{D}-\mathrm{S}}$ was then fitted to a subset of 75 species for which those data were available (Model 2).

The 17 'partially desiccation tolerant' species were then excluded and Binary Logistic Regression was used to analyse a third dataset assessing response to desiccation against habit, habitat, fresh SMC, DW, SCR and $P_{\mathrm{D}-\mathrm{S}}$ for 139 species from this study and an additional 59 Australian species assessed by Hamilton et al. (2013). For this analysis, a logit link function was employed and the Hosmer-Lemeshow goodness-of-fit test was used to check model fit. All analyses were conducted in Minitab® v16.2.4 (Minitab Inc. Pennsylvania).

\section{Development of a key to desiccation response}

A step-by-step key to assigning the most likely desiccation response to untested species was developed using the most informative characteristics from this study combined with characteristics identified as strongly associated with desiccation tolerance or sensitivity in previous studies, i.e. dry weight and fresh seed moisture content (Hong and Ellis 1996; Ellis et al. 2007), habit and physical dormancy (Tweddle et al. 2003), $P_{\mathrm{D}-\mathrm{S}}$ (Daws et al. 2006) and genus (Wyse and Dickie 2018). To test the utility of the key, we assumed no prior data on genus was available (Step 1) then applied Steps 2 to 6 in consecutive order to the 156 species from this study for which the desiccation response had been determined. Species assigned to a desiccation response were removed from the pool of species at each step (regardless of whether the assignment was correct or incorrect) and the subsequent step was applied to the species remaining till no further species could be assigned.

\section{Results}

\section{Germination}

Of the 313 species tested, a germination response $\geq 50 \%$ was achieved for 162 species from 63 families (Online Resource 1); the remaining species germinated too poorly to enable reliable assessment of storage behaviour. For 22 species with germination $\geq 50 \%$, pre-treatments or germination conditions differed between successive experiments due to attempts to control contamination or improve germination, or due to experimental error. These differences were ignored for the purpose of assigning storage behaviour if the seed germinated as well, or better, under the altered conditions as they did under the original conditions. Where the initial germination test was conducted on water agar and subsequent tests were on agar containing $250 \mathrm{ppm} \mathrm{GA}_{3}$, any reduction in germination in the latter was assumed to be due to the storage treatment given that $\mathrm{GA}_{3}$ is a germination promoter and has not been observed to be toxic in this lab at the concentration used.

Of the 93 species for which fresh seeds were sown on agar, at least 35\% appeared to be dormant based on the time to $50 \%$ of final germination exceeding 30 days (Online Resource 
1 ; seeds sown in propagation mix could not be evaluated for dormancy as it was not possible to observe the timing of radicle emergence). Drying appeared to induce dormancy for Diospyros pentamera (germination significantly reduced after drying $(P<0.05)$ but seeds still viable) and to break dormancy for Hymenosporum flavum and two accessions of Rhodomyrtus psidioides (germination faster or significantly greater after drying $(P<0.05)$; Online Resource 1). Freezing appeared to break residual or drying-induced dormancy for Diplocyclos palmatus, Entolasia marginata, Ficus virens, Helmholtzia glaberrima and for one of two accessions of Neoachmandra cunninghamii (germination significantly greater after freezer storage $(P<0.05)$ than after drying; Online Resource 1).

\section{Response to drying}

Of the 162 species with a germination response $\geq 50 \%, 36(22 \%)$ were desiccation sensitive, 103 (64\%) were desiccation tolerant, and $17(10 \%)$ were partially desiccation tolerant. The behaviour of six species (4\%) was uncertain. Desiccation sensitivity was found in 20 families and was common in Lauraceae (4 of 5 species) and Sapindaceae (4 of 6 species; Table 1). Desiccation sensitive seeds tended to have larger dimensions than desiccation tolerant seeds and were more likely to possess such features as a woody endocarp, green embryo, or a thin seed coat surrounding a large embryo (Figs. 3 and 4). The response to desiccation was consistent among species for 14 of the 18 genera in which two or more species were studied (Acronychia, Argyrodendron, Cordyline, Dysoxylum, Ficus, Fontainea, Flindersia, Parsonsia, Pittosporum, Psychotria, Rhodamnia, Senna, Solanum and Vesselowskya; Table 1). For the remaining four genera (Ceratopetalum, Cryptocarya, Diospyros and Alphitonia), the desiccation response was variable among species. The response to desiccation was consistent among genera within 12 of the 26 families for which two or more genera were studied; responses were variable among genera in 14 families.

\section{Response to freezing}

A total of 105 fully or partially desiccation tolerant species were tested for their tolerance of freezing: 73 species (70\%) were tolerant of short-term storage (1 to 36 months) at $-20{ }^{\circ} \mathrm{C} ; 27$ species $(26 \%)$ were either sensitive to freezing or short-lived in storage (Table 1, Online Resource 1). The response of 5 species was uncertain. Freezing sensitive/ short-lived species were found in 14 families and were most common in the Myrtaceae (4 of the 8 species tested).

\section{Assessment of desiccation response by plant habit and habitat}

Tree species produced a significantly higher proportion of desiccation sensitive seeds $(42 \%)$ than herbs $(7 \%)$, climbers $(17 \%)$, shrubs $(5 \%)$ or shrub/trees $(17 \%)(P=0.006$, $\mathrm{n}=156$; Fig. 5a). The relationship between habit and desiccation sensitivity remained when the dataset from the present paper was combined with 59 species from the earlier Australian study (Hamilton et al. 2013; Fig. 5b).

Species with a habitat range restricted to wet rainforests, or occurring in both wet and dry rainforests, had a higher proportion of desiccation sensitive species (30 and 25\%, respectively) than species restricted to dry rainforest or with a distribution extending to non-rainforest habitat ( 0 and $11 \%$, respectively; Fig. $6 \mathrm{a}$ ); however, the differences between 


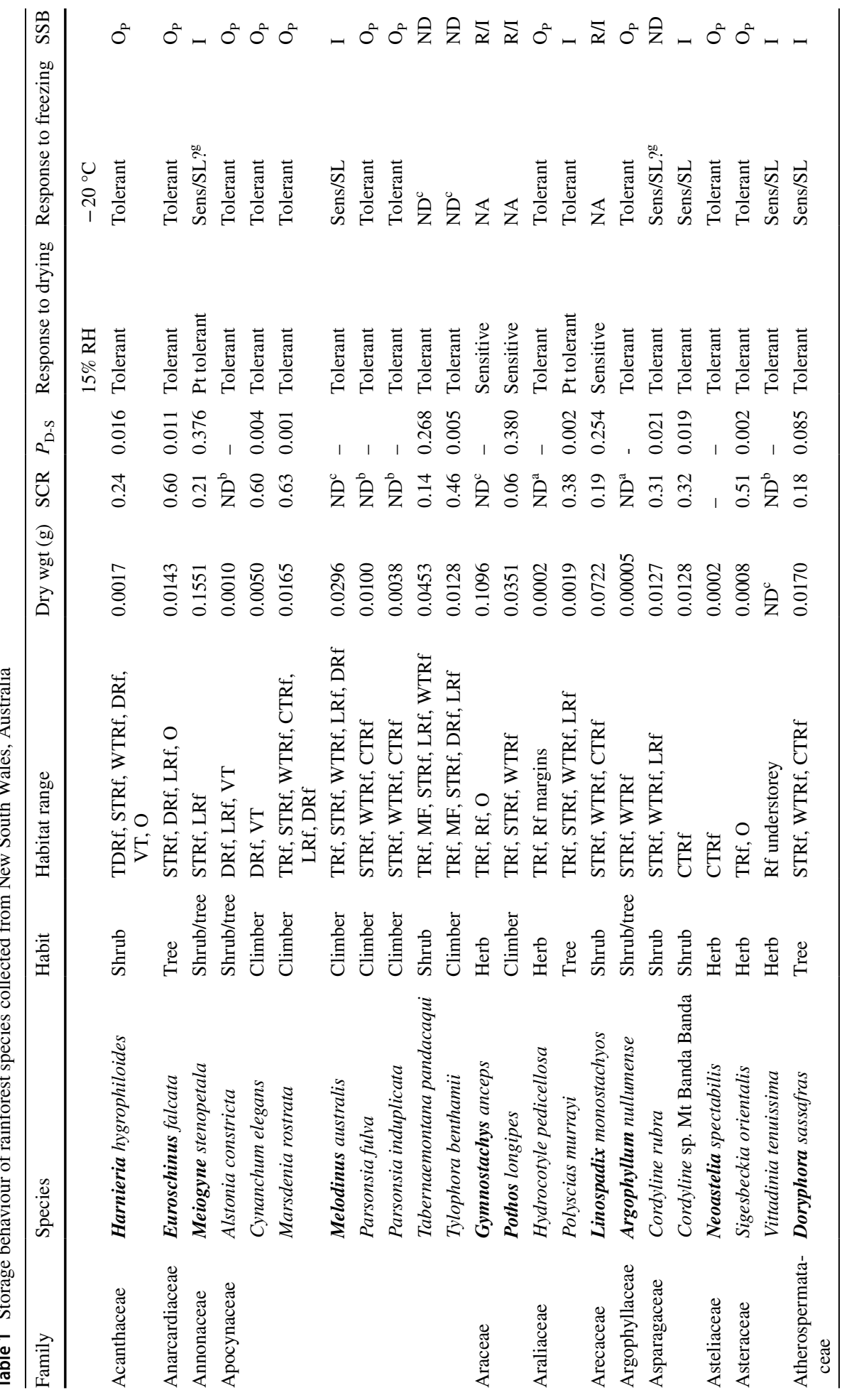




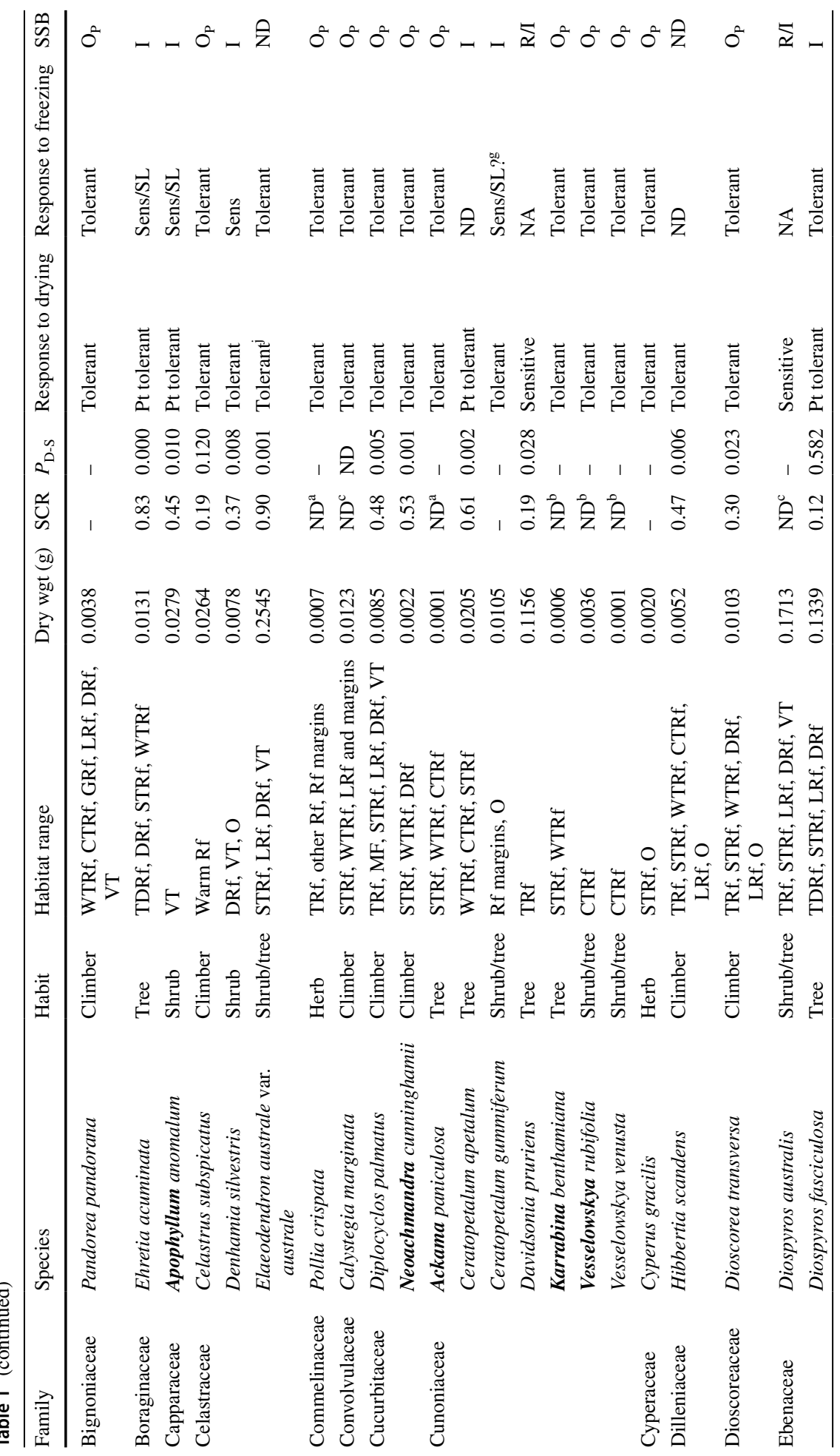




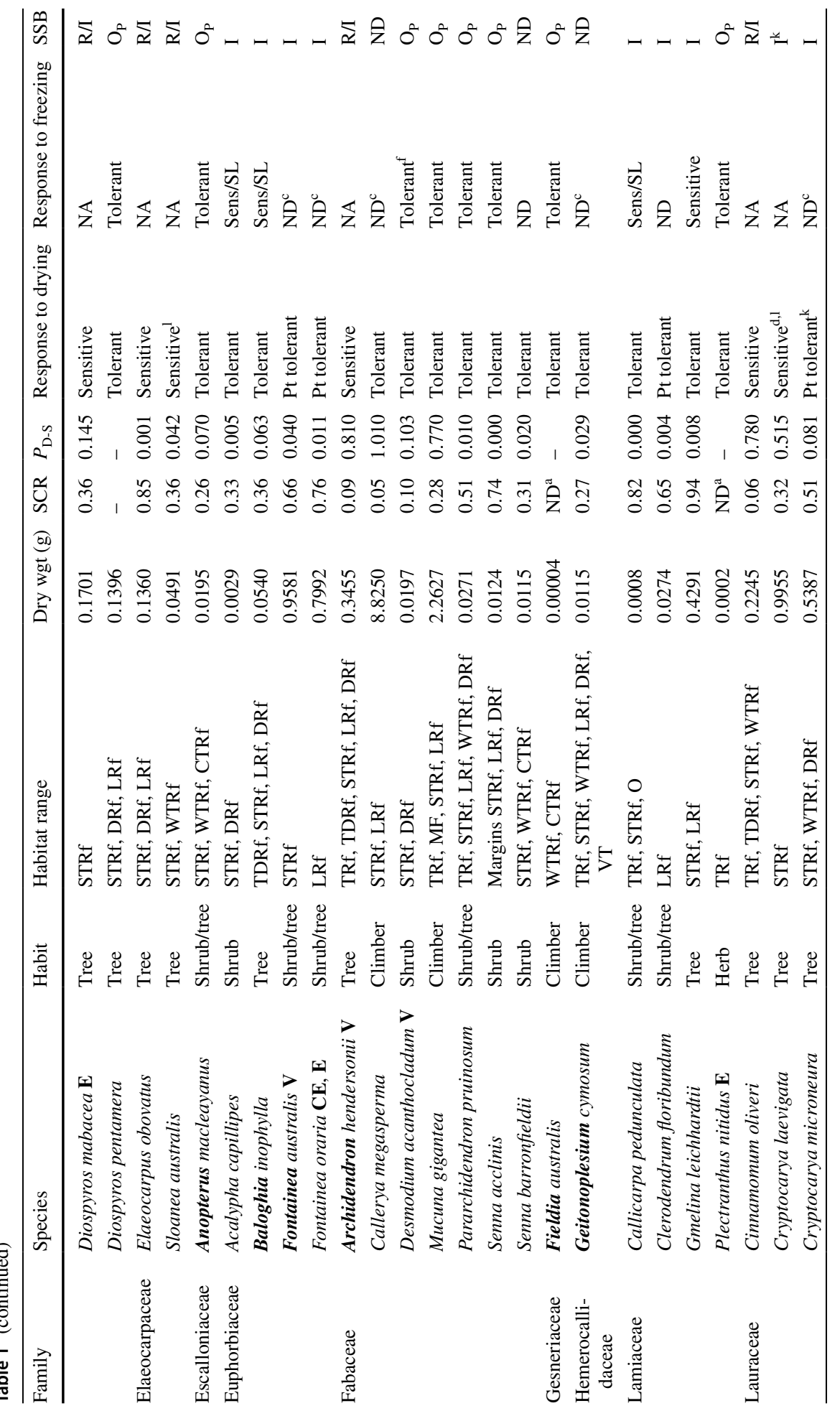




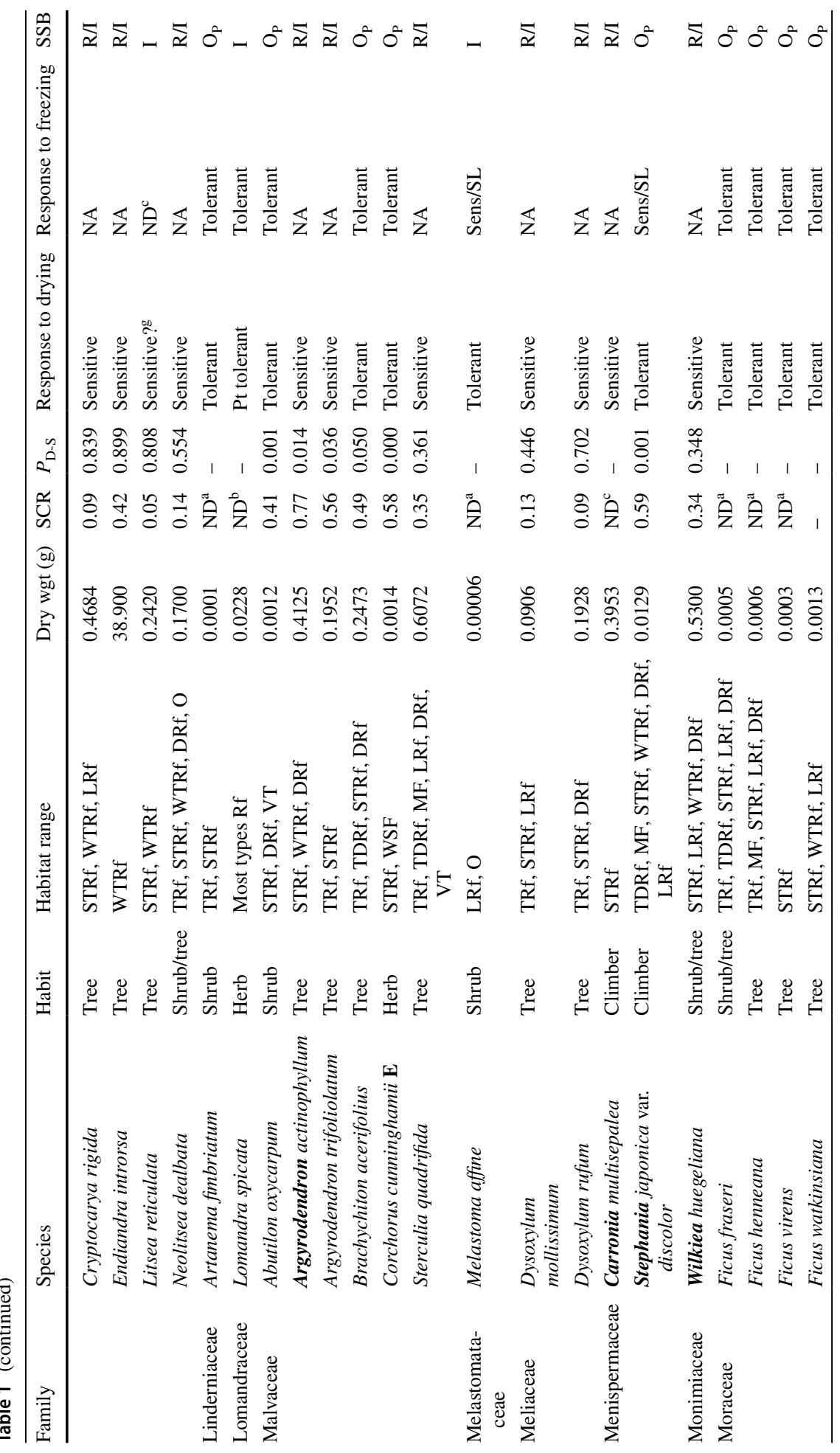




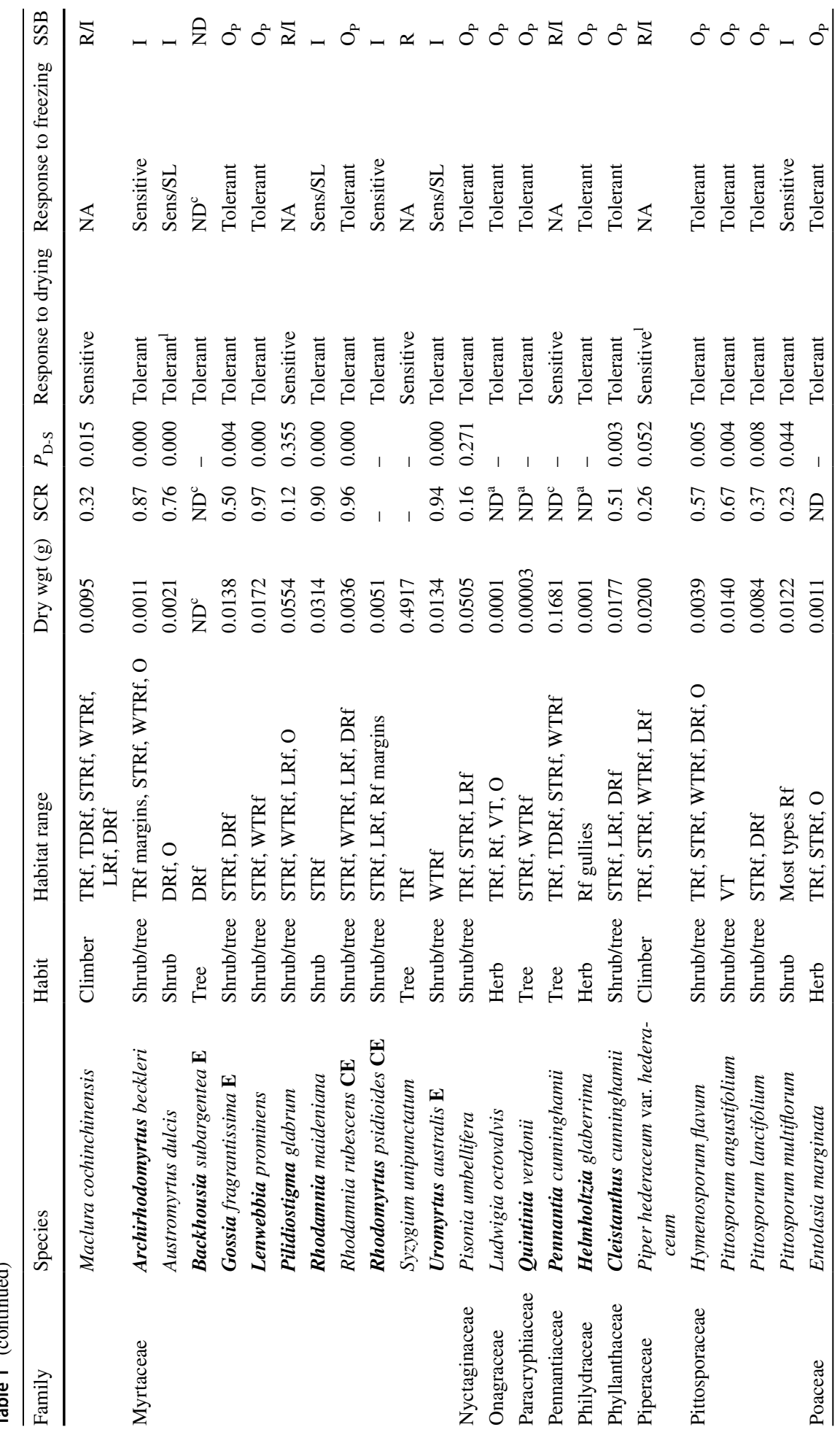




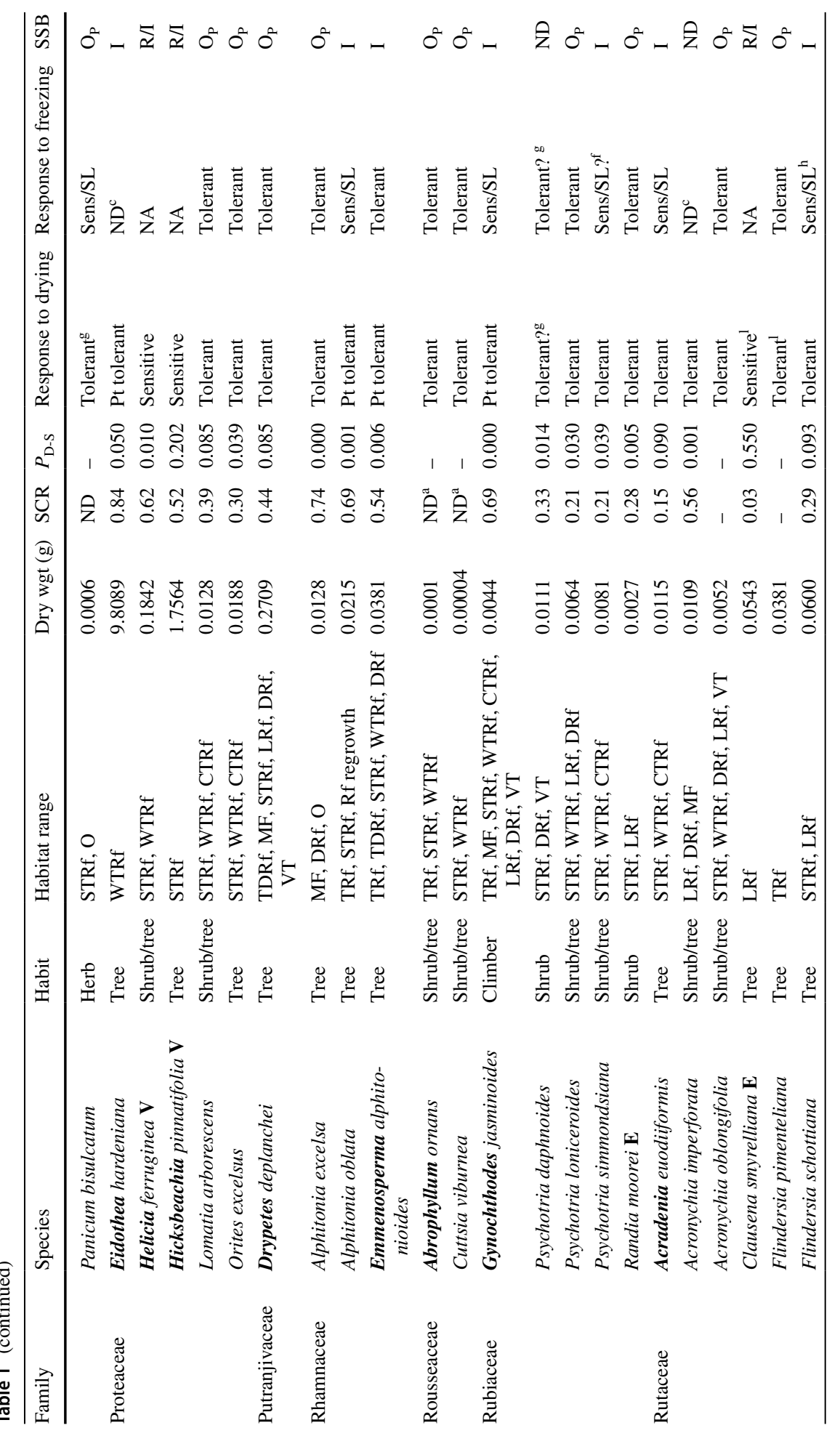




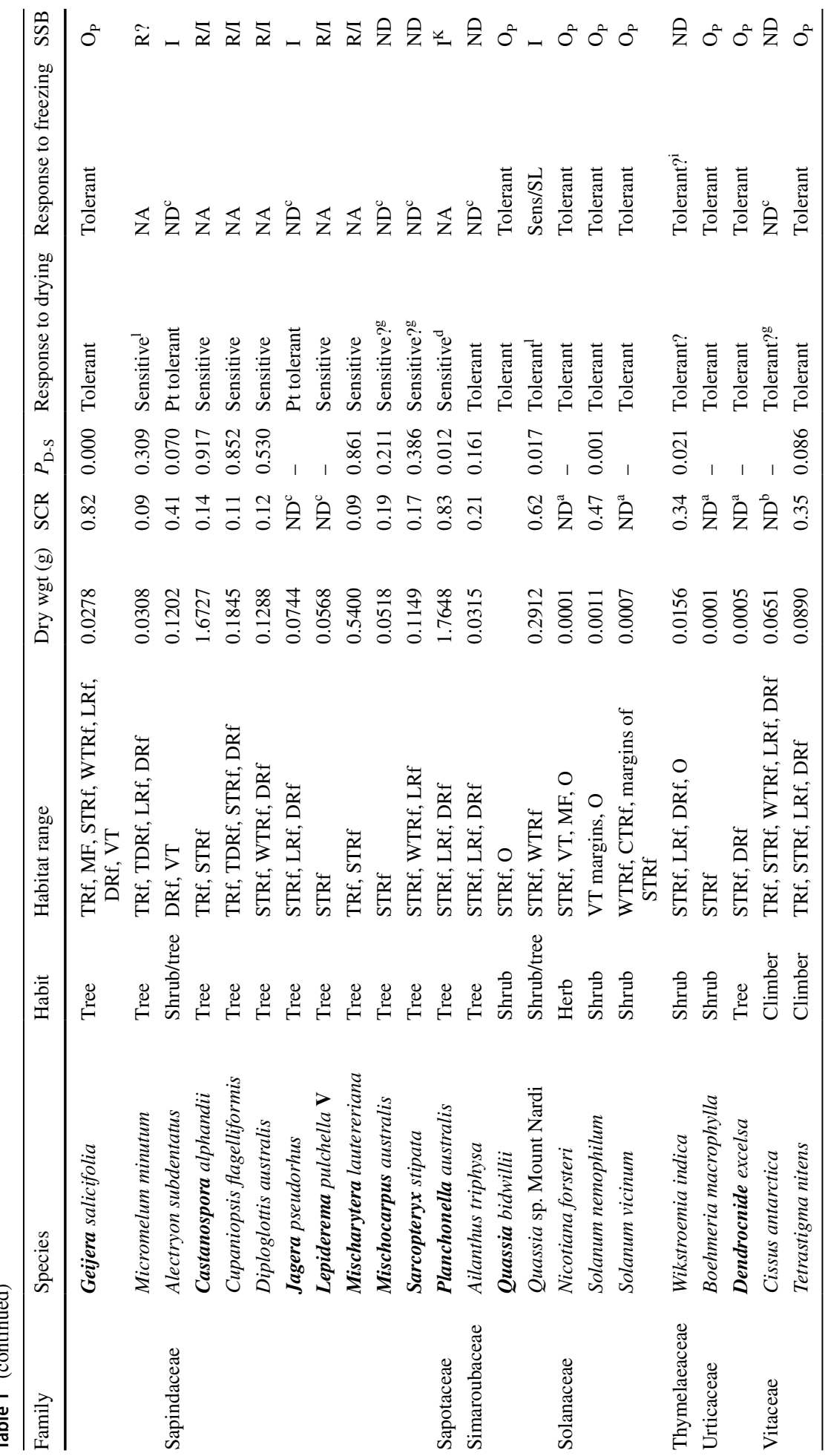




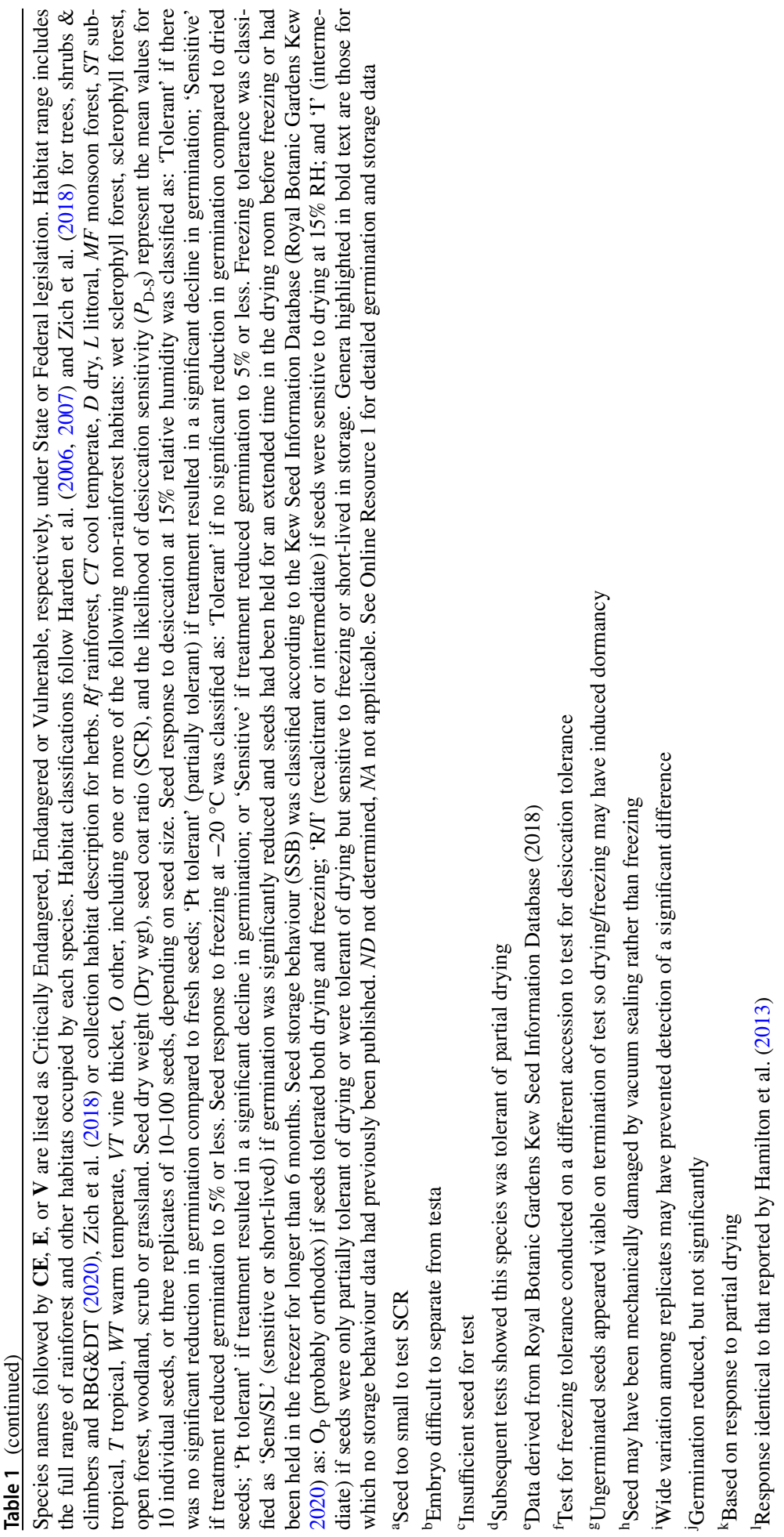


habitat categories were not significant $(P=0.099, \mathrm{n}=156)$. This pattern was repeated in the combined dataset (Fig. 6b).

\section{Assessment of desiccation response by seed characteristics}

The values for fresh SMC, DW, SCR and $P_{\mathrm{D}-\mathrm{S}}$ for each desiccation response category overlapped in range but, in all cases, the median values for desiccation sensitive seeds were significantly different to desiccation tolerant or partially tolerant seeds (Fig. 7).

Fresh SMC ranged from 9.7 to $85.6 \%$ for desiccation sensitive seeds, 3.7 to $63.6 \%$ for desiccation tolerant seeds and 7.2 to $62.7 \%$ for partially desiccation tolerant seeds. The median fresh SMC of desiccation sensitive seeds was significantly greater than both desiccation tolerant $(P=0.000, \mathrm{n}=79)$ and partially desiccation tolerant seeds $(P=0.001$, $\mathrm{n}=46$; Fig. 7a). Low fresh SMC was a good indicator of desiccation tolerance; of 39 species with a fresh SMC $<29 \%$, only 1 was desiccation sensitive compared to $50 \%$ of the 60 species with a fresh $\mathrm{SMC} \geq 29 \%$.

DW ranged from 0.01 to $38.9 \mathrm{~g}$ for desiccation sensitive seeds, $<0.0001$ to $8.8 \mathrm{~g}$ for desiccation tolerant seeds, and 0.002 to $9.8 \mathrm{~g}$ for partially desiccation tolerant seeds. The median DW of desiccation sensitive seeds was significantly greater than both desiccation tolerant $(P=0.000, \mathrm{n}=137)$ and partially desiccation tolerant seeds $(P=0.033, \mathrm{n}=52$; Fig. 7b). Very light-weight seeds were most likely to be desiccation tolerant. Of the 84 species with a seed dry weight $<0.02 \mathrm{~g}$, only 1 was desiccation sensitive; the remainder were fully $(95 \%)$ or partially (4\%) desiccation tolerant. In contrast, of the 74 species with seed dry weight $\geq 0.02 \mathrm{~g}, 47 \%$ were desiccation sensitive.

Separation of the embryo and testa was not possible for very small seeds, nor for seeds in which the embryo/endosperm was firmly attached to the testa or in which the testa was folded into the embryo. SCR and $P_{\mathrm{D}-\mathrm{S}}$ were therefore determined for 109 species ranging in dry weight from 0.0008 to $38.9 \mathrm{~g}$. SCR ranged from 0.03 to 0.83 for desiccation sensitive seeds, 0.05 to 0.97 for desiccation tolerant seeds and 0.12 to 0.84 for partially desiccation tolerant seeds. The median SCR for desiccation sensitive seeds was significantly lower than both desiccation tolerant $(P=0.000, \mathrm{n}=89)$ and partially desiccation tolerant seeds $(P=0.000, \mathrm{n}=43$, Fig. $7 \mathrm{c})$ while the median $P_{\mathrm{D}-\mathrm{S}}$ was significantly higher than both desiccation tolerant $(P=0.000, \mathrm{n}=89)$ and partially desiccation tolerant seeds $(P=0.000$, $\mathrm{n}=43$; Fig. 7d). Low $P_{\mathrm{D}-\mathrm{S}}$ values were useful for predicting desiccation response; of 39 species with $P_{\mathrm{D}-\mathrm{S}}<0.01$, all were either desiccation tolerant $(82 \%)$ or partially tolerant (18\%). The value used by Daws et al. (2006) to predict desiccation sensitivity $\left(P_{\mathrm{D}-\mathrm{S}}>0.5\right)$ correctly predicted desiccation sensitivity for 12 of 16 species $(75 \%)$. When results were categorised by plant habit, $P_{\mathrm{D}-\mathrm{S}}>0.5$ correctly predicted desiccation sensitivity for 10 of 12 tree species (83\%). A lower value of $P_{\mathrm{D}-\mathrm{S}}>0.3$ correctly predicted desiccation sensitivity for 13 of 15 tree species $(87 \%)$.

\section{Seed characteristics as predictors of desiccation response}

Similar relationships between desiccation response and fresh SMC, DW and $P_{\mathrm{D}-\mathrm{S}}$ were found in the dataset combining seed characteristics from 348 rainforest species in Australia, Panama and Southern China. The median values for fresh SMC, DW and $P_{\mathrm{D}-\mathrm{S}}$ of desiccation sensitive seeds were all significantly greater than for desiccation tolerant seeds ( $P=0.000$ in all cases; $\mathrm{n}=286,347$ and 299 , respectively), while the median value for SCR 

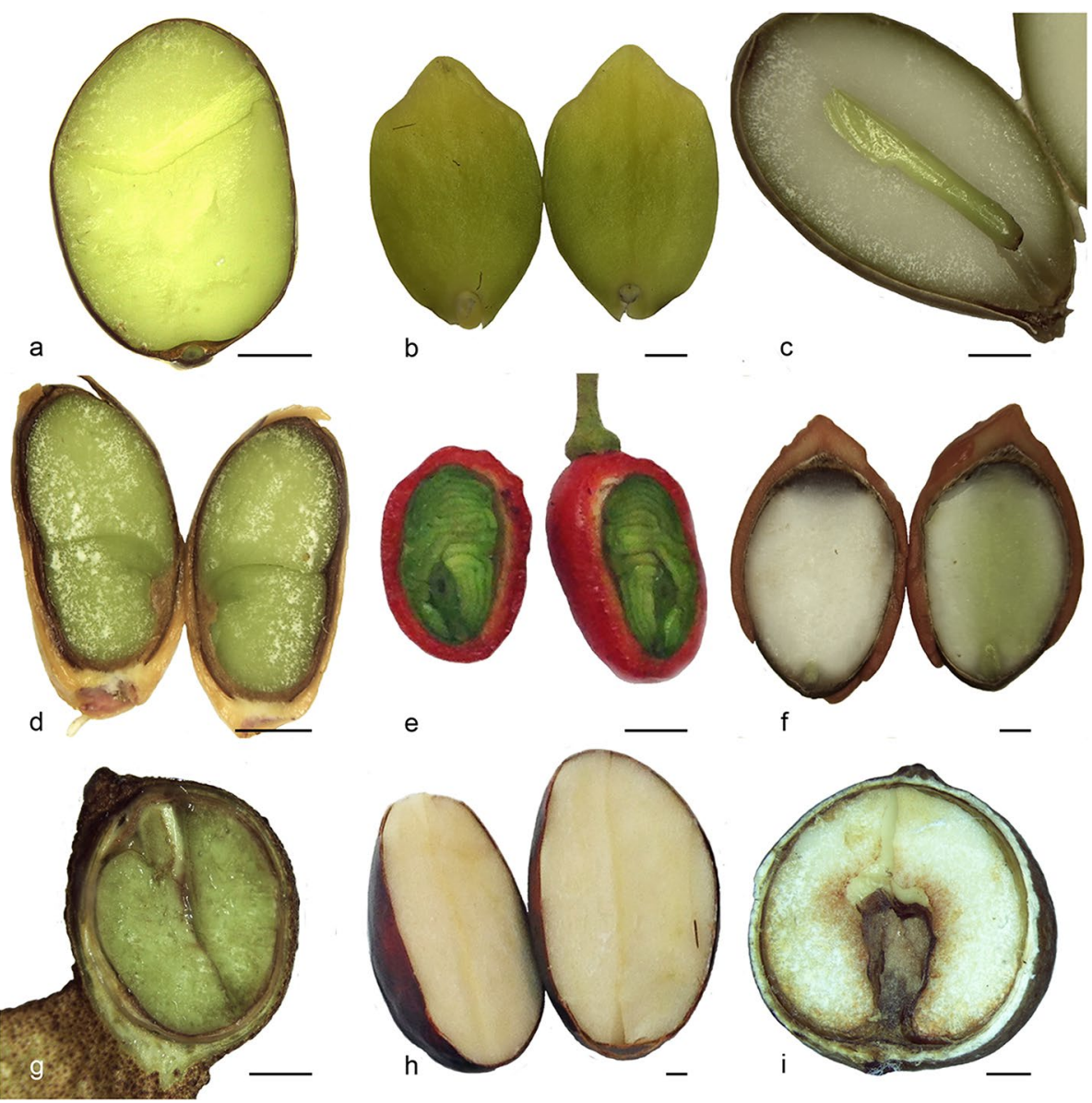

Fig. 3 A selection of seeds found sensitive to drying to equilibration with $15 \%$ relative humidity: a Harpullia pendula; b Helicia ferruginea; c Pennantia cunninghamii; d Lepiderema pulchella; e Micromelon minutum; f Sloanea woollsii; $\mathbf{g}$ Argyrodendron trifoliolatum; $\mathbf{h}$ Cupaniopsis flagelliformis; and $\mathbf{i}$ Cryptocarya foetida. Scale bar $=2 \mathrm{~mm}$

was significantly less $(P=0.000, \mathrm{n}=299)$. Seeds with a fresh $\mathrm{SMC}<20 \%$ were desiccation tolerant (Fig. 8a) while $98 \%$ of species with DW $<0.02 \mathrm{~g}$ were fully or partially desiccation tolerant (Fig. $8 \mathrm{~b}$ ). A $P_{\mathrm{D}-\mathrm{S}}$ value $>0.5$ correctly predicted desiccation sensitivity for 78 of 93 species (84\%) in the combined dataset, and for 56 of 64 tree species $(88 \%)$. Of the 15 species that had a $P_{\mathrm{D}-\mathrm{S}}>0.5$ but were desiccation tolerant, seven were from the Fabaceae, a family that has a high proportion of species with physically dormant and orthodox seeds. The lower value of $P_{\mathrm{D}-\mathrm{S}}>0.3$ correctly predicted desiccation sensitivity for $79 \%$ of all species, or $86 \%$ of trees, in that range. A $P_{\mathrm{D}-\mathrm{S}}$ value $<0.01$ correctly predicted desiccation tolerance for all 70 species in that range (Fig. 8c). 


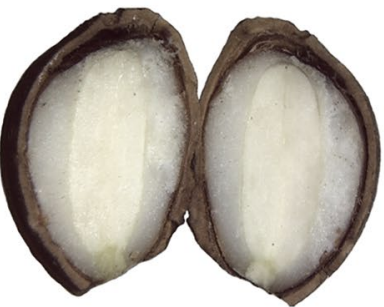

a

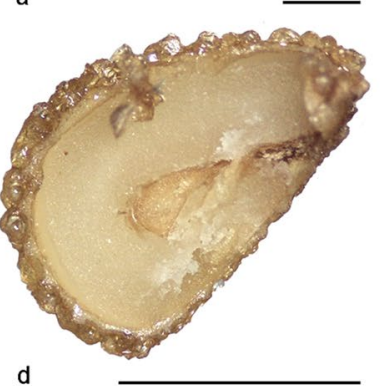

d

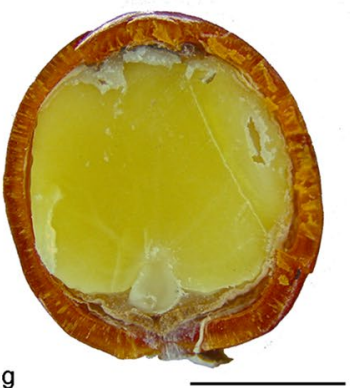

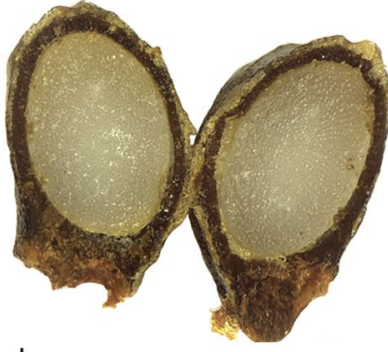

b

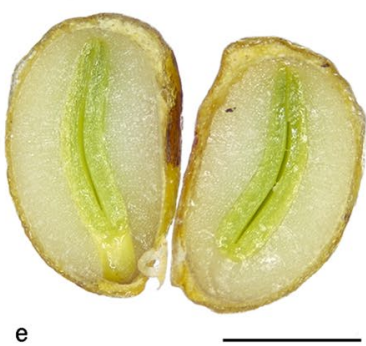

e

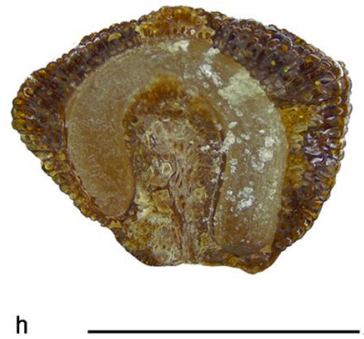

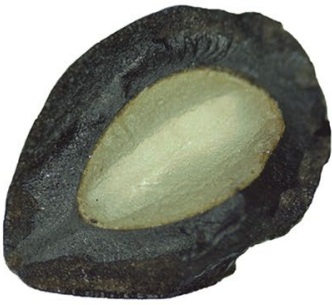

C

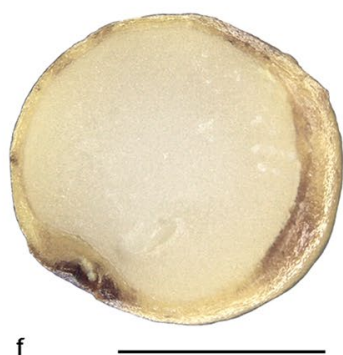

f

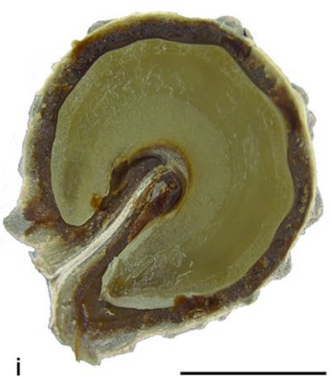

Fig. 4 A selection of seeds found tolerant of drying to equilibration with $15 \%$ relative humidity: a Akania bidwillii; b Hibbertia scandens; c Geijera salicifolia; d Rhodomyrtus psidioides; e Denhamia sylvestris; $\mathbf{f}$ Pittosporum multiflorum; $\mathbf{g}$ Emmenosperma alphitonioides; h Archirhodomyrtus beckleri; and i Stephania japonica var. discolor. Scale bar $=2 \mathrm{~mm}$

\section{Modelling of responses}

Ordinal logistic regression (OLR) of desiccation response for 156 Australian species against latitude, rainfall, mean and maximum temperature, habit, habitat category, fruit characteristics and seed dry weight (Model 1) identified two significant predictors-habit (tree, $P=0.004$ ) and fruit type (fleshy, $P<0.001$ ). With odds ratios of 5.3 and 4.8 , respectively, these two factors significantly increased the likelihood of desiccation sensitive seeds compared to plants with other habits or dry fruit. Pearson and Deviance goodness-of-fit tests indicated the model fitted the data well $(P=0.645$ and 0.452 , respectively; $\mathrm{n}=156)$, with $70.2 \%$ concordance between the response variable and predicted probabilities. OLR of a smaller dataset combining habit and fleshiness with fresh SMC and $P_{\mathrm{D}-\mathrm{S}}$ identified both fresh SMC and $P_{\mathrm{D}-\mathrm{S}}$ as the only significant predictors $(P=0.001$ and 0.009 , respectively; $\mathrm{n}=75$ ). Note that this dataset excluded many small and low weight seeds for which fresh SMC and $P_{\mathrm{D}-\mathrm{S}}$ were not determined. Odds ratios of 1.04 and 32.8, respectively, 


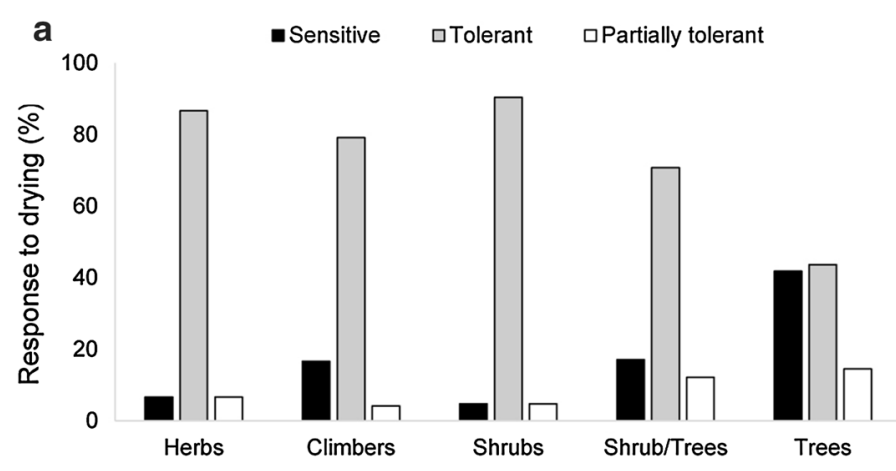

b 100

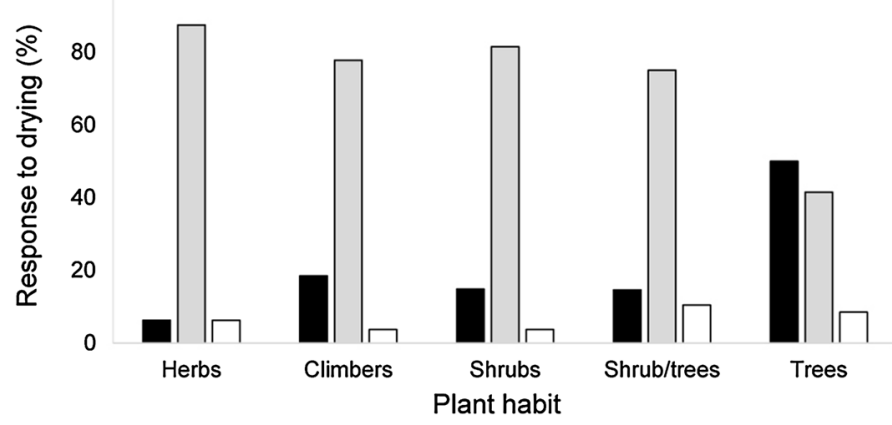

Fig. 5 The relative proportions of desiccation sensitive, tolerant and partially tolerant seeds among Australian rainforest species with habits described as herb, climber, shrub, shrub/tree or tree for: a species from this study only ( $\mathrm{n}=12,23,22,35$ and 52 , respectively); and $\mathbf{b}$ species from this study combined with those published in Hamilton et al. (2013; $n=16,27,27,48$ and 94, respectively)

indicated a small increase in the likelihood of desiccation sensitivity with each percentage point increase in SMC and a large increase in the likelihood of desiccation sensitivity with an increase in $P_{\mathrm{D}-\mathrm{S}}$. Both Pearson and Deviance goodness-of-fit tests indicated the model fitted the data well ( $P=0.733$ and 0.991 , respectively) with $84 \%$ concordance between the response variable and predicted probabilities.

Binary Logistic Regression (BLR) of desiccation response (desiccation tolerant or sensitive only) against habit, habitat, dry weight, fresh SMC, SCR and $P_{\mathrm{D}-\mathrm{S}}$ for Australian species from the present study and Hamilton et al. (2013) also identified fresh SMC and $P_{\mathrm{D}-\mathrm{S}}$ as the only significant predictors $(P<0.001$ in both cases; $n=118)$. Odds ratios of 0.93 and 0.00 , respectively, in this case suggested fresh SMC was the more influential variable, with an increase in fresh SMC reducing the likelihood of desiccation tolerance. The Hosmer-Lemeshow goodness-of-fit test indicated the model fitted the data well $(P=0.074)$, with $92 \%$ concordance between the response variable and predicted probabilities. Note that 3 palms were excluded from this analysis as that habit category was not present in both data sets. 


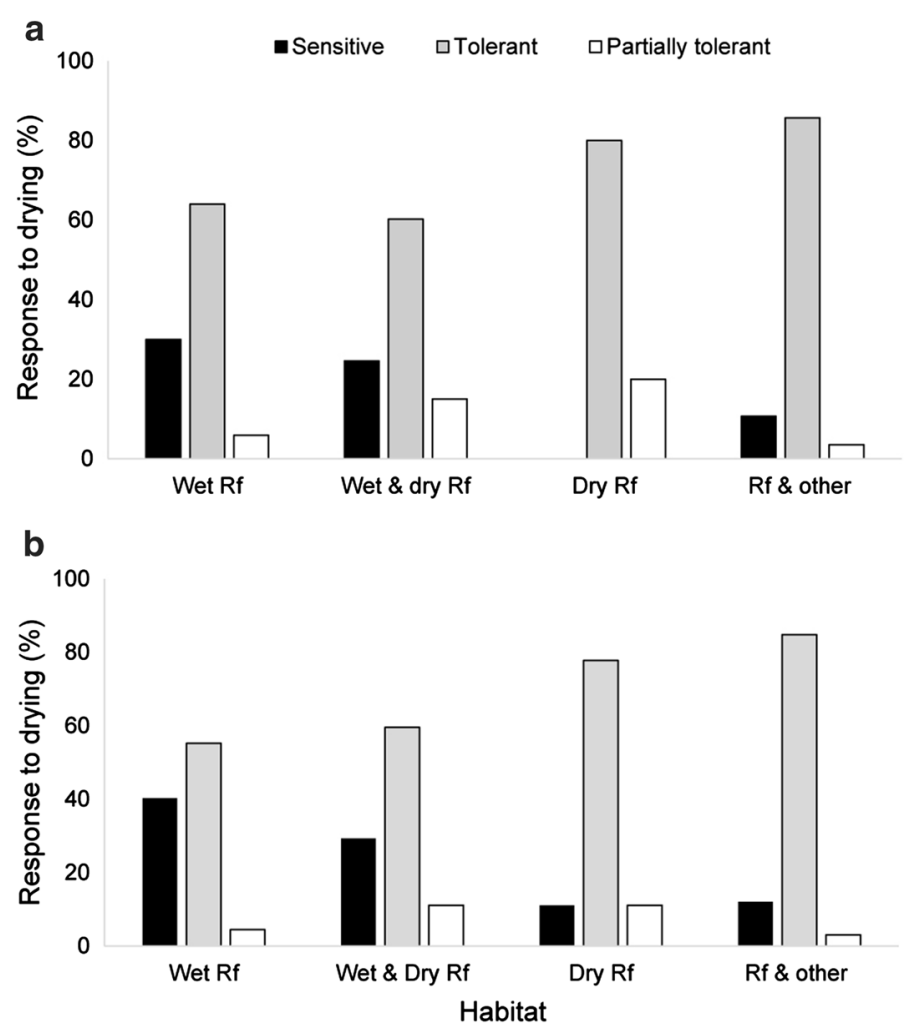

Fig. 6 The relative proportions of desiccation sensitive, tolerant and partially tolerant seeds among Australian plant species occurring in wet rainforest only, both wet and dry rainforest, dry rainforest only, or a combination of rainforest and non-rainforest habitats for: a species from this study only $(\mathrm{n}=50,73,5$ and 28 , respectively); and b species from this study combined with those published in Hamilton et al. $(2013 ; n=67$, 99,9 and 33, respectively)

\section{Key to desiccation response}

The decision key developed to aid determination of the most likely response to desiccation consisted of seven consecutive steps incorporating an assessment of: the known response of other species in the genus; seed coat permeability; seed dry weight; fresh seed moisture content; $P_{\mathrm{D}-\mathrm{S}}$; the presence or absence of a woody endocarp; and embryo colour (Table 2). Of the 156 species used to test the utility of the key, 141 were able to be assigned to a desiccation response without germination testing; 127 of those (90\%) were assigned correctly. Of the 100 species assigned a 'Desiccation Tolerant' response, $98 \%$ had been shown in this study to be fully (92 spp.) or partially (6 spp.) tolerant of desiccation to 3-7\% moisture content. Of the 15 species not accounted for, ten lacked data on dry weight, fresh seed moisture content or $P_{\mathrm{D}-\mathrm{S}}$. 

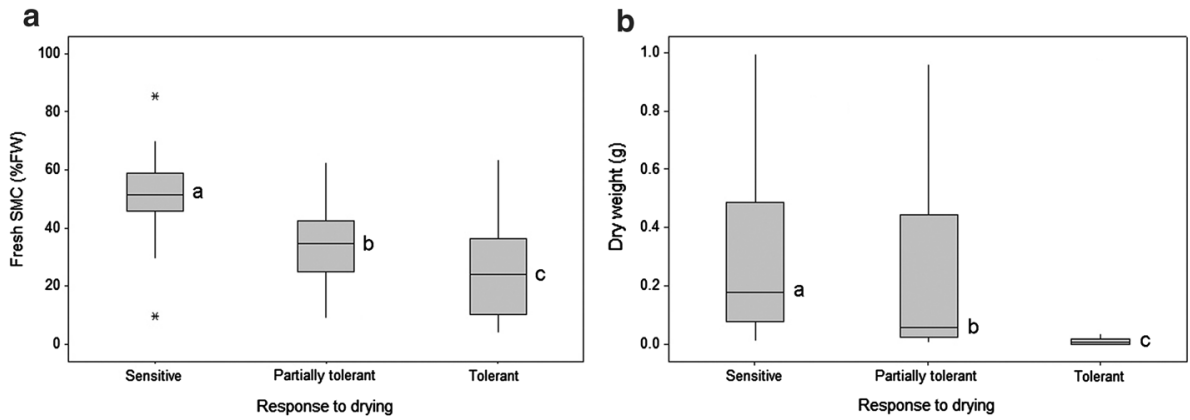

C

d
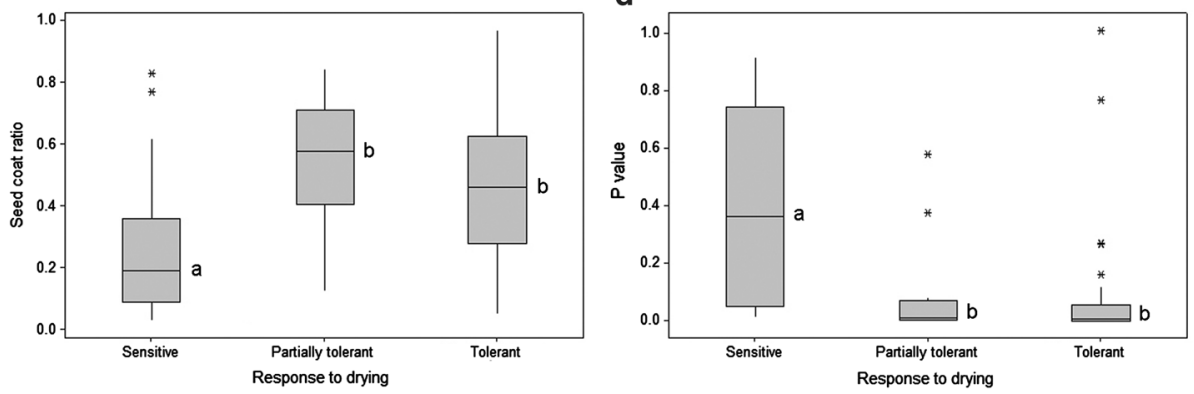

Fig. 7 The response of seeds to drying in relation to: a fresh seed moisture content (\% fresh weight basis); b seed dry weight; c seed coat ratio; and $\mathbf{d} P_{\mathrm{D}-\mathrm{S}}$ (or 'P value'), a figure representing the likelihood of desiccation sensitivity based on seed coat ratio and dry weight. Different superscripts within each chart represent significant differences $(P \leq 0.001)$ in median values among the desiccation response categories. Data were analysed using pairwise non-parametric one-way analysis of variance (Kruskal and Wallis, 1952) in Minitab v16

\section{Discussion}

The need to preserve rainforest species in ex situ collections has become critical to mitigate on-going losses in diversity through habitat loss, disease and a changing climate. In eastern Australia, prolonged drought and catastrophic fires have recently added to these pressures with the 2019-20 bush fire season burning 54\% of the World Heritage listed Gondwana Rainforests in New South Wales (NSW DPIE 2020). Seed banking may be a useful technique to apply in this context but information on the suitability of seed for banking has been lacking for many rainforest species. The work presented here provides insight into the seed storage behaviour of 162 native Australian rainforest species from 136 genera and 63 families. For most of the species tested, and 55 of the genera, such data had not previously been published (Table 1; Sommerville et al. 2018). Given that the known storage behaviour of species within a genus is a useful predictor for untested species in that genus (Wyse and Dickie 2018), the results may potentially be extrapolated to many other species and provide a strong step forward in our efforts to conserve rainforest flora. For eight genera in the Myrtaceae, the work also provides the urgent preliminary research needed to conserve species on the brink of extinction due to Myrtle Rust.

There remain many genera of tropical and subtropical rainforests, however, for which no data on storage behaviour are available (Sommerville et al. 2018). For species in those genera, the key to desiccation response presented here (Table 2) will provide a useful aid to 


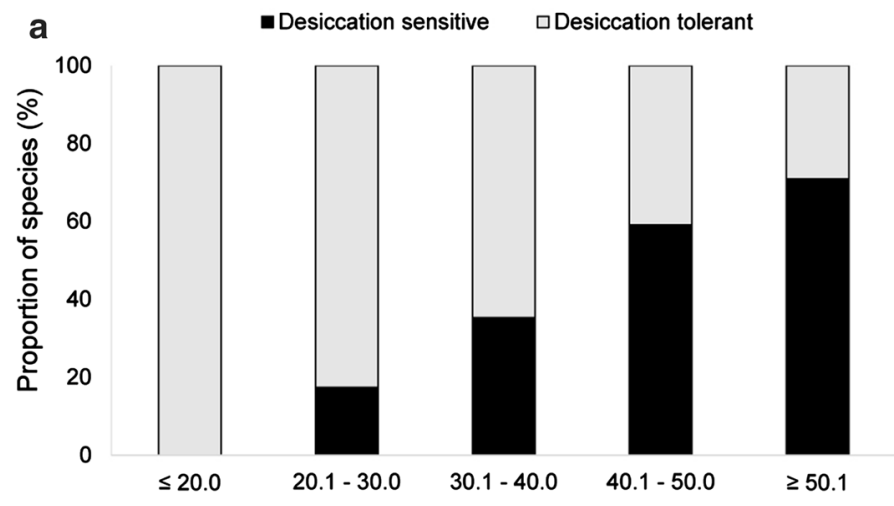

Fresh seed moisture content (\% fresh weight)

b

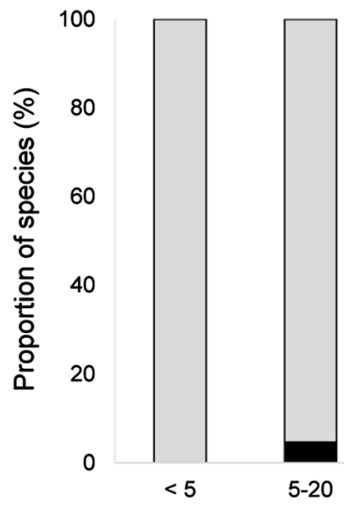

Desiccation sensitive

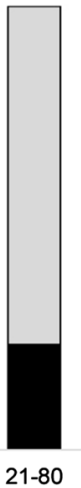

口Desiccation tolerant

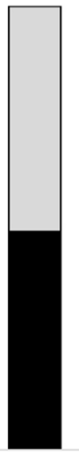

81-250

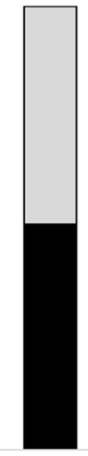

251-800

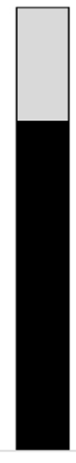

$>800$

\section{Dry weight (mg)}

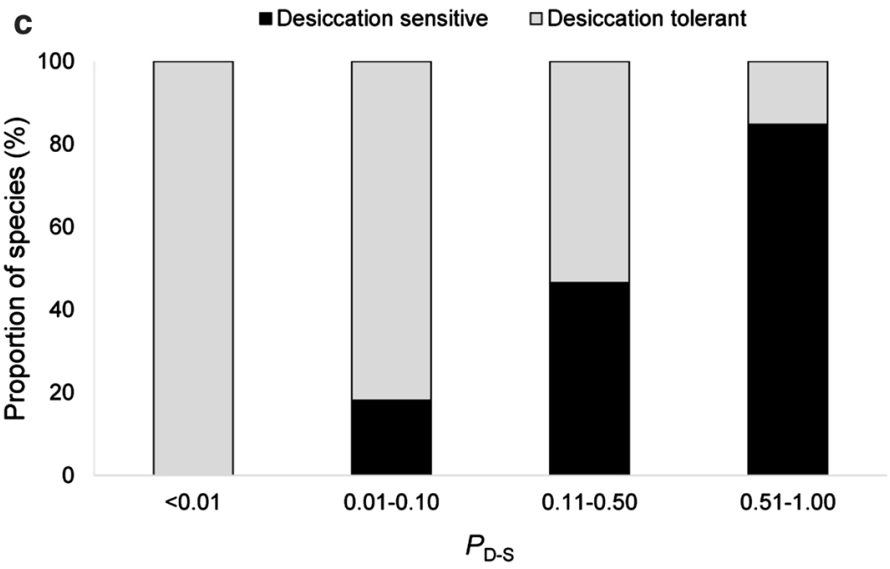

Fig. 8 The relative proportions of desiccation sensitive and desiccation tolerant seeds in relation to a fresh seed moisture content $(\mathrm{n}=289)$; b seed dry weight $(\mathrm{n}=364)$ and $\mathbf{c} P_{\mathrm{D}-\mathrm{S}}$ (a figure representing the likelihood of desiccation sensitivity based on seed coat ratio and dry weight; $n=313$ ) for rainforest species occurring in Australia, China and Panama 
quickly identifying those species likely to be suitable for standard seed banking and those likely to require alternative conservation measures. As in previous studies, the relationships observed here between storage behaviour and fresh seed moisture content, dry weight and $P_{\mathrm{D}-\mathrm{S}}$ only allowed reliable prediction of desiccation response at one or both ends of the range for each variable (e.g. Daws et al. 2006; Ellis et al. 2007; Lima et al. (2014); the difficulty in predicting storage responses for species falling within the middle of those ranges remained. While other characteristics, such as tree habit and fleshy fruit, were shown to significantly increase the likelihood of desiccation sensitivity, these still did not make reliable predictors for the purpose of seed banking. The key resolves these problems by combining the most useful range of values for the best predictors into a step-by-step process for assigning a desiccation response.

For many species, the most likely desiccation response may be determined within $48 \mathrm{~h}$ without germination testing, enabling more rapid identification of seeds that are suitable for banking. As the determination of desiccation response by direct testing can take anywhere from a couple of months to a couple of years, the key therefore has the potential to greatly reduce the time and effort required to determine which rainforest seeds are suitable for banking. At this stage, however, it cannot be used to assess whether a species has orthodox storage behaviour (i.e. with longevity improved by both drying and cold storage) unless other species in the genus have previously been assessed (Table 2, Step 1). Further work is needed to find seed characteristics that could be used to identify species that are freezing sensitive without germination testing; therefore, for the moment at least, tests to confirm tolerance of cold storage will still be required for species from previously unstudied genera.

Wyse and Dickie's (2018) finding that the storage behaviour of species in a genus is a useful predictor of storage behaviour for untested species in that genus was supported to a large extent by the results of this study. We found the response to desiccation to be consistent for 14 of the 18 genera in which two or more species were studied (Acronychia, Argyrodendron, Cordyline, Dysoxylum, Ficus, Fontainea, Flindersia, Parsonsia, Pittosporum, Psychotria, Rhodamnia, Senna, Solanum and Vesselowskya; Table 1). For the remaining genera (Ceratopetalum, Cryptocarya, Diospyros and Alphitonia), the desiccation response was variable among species.

Differences in desiccation response among species in the same genus can sometimes be related to differences in fruit or seed structure. Species in the genus Syzygium, for example, generally produce fleshy fruits and desiccation sensitive seeds (Royal Botanic Gardens Kew 2020). Syzygium anisatum, however, has a dry fruit and, though the embryo is similar in structure to some other Syzygium species (Craven and Biffen 2005), it is tolerant of drying (unpublished data). In three species of Derris - all tropical lianes—investigated by Jayasuriya et al. (2012), one species with an impermeable seed coat (D. scandens) was desiccation tolerant, but one of the two species with a permeable seed coat (D. trifoliata) was desiccation sensitive. Differences in fruit and seed structure may also be a good indication of differences in desiccation response among genera in families that have predominately orthodox seeds. Species in the Fabaceae and Malvaceae, for example, generally produce hard-coated impermeable seeds and $>90 \%$ of the species tested so far have been found to be orthodox in their storage behaviour (Dickie and Pritchard 2002). Three genera from those families investigated in this study (Archidendron in Fabaceae, and Argyrodendron and Sterculia in Malvaceae) had species with permeable seed coats that were desiccation sensitive. Fruit and seed structure may therefore be combined with phylogeny to provide a useful indicator of seed storage behaviour. 


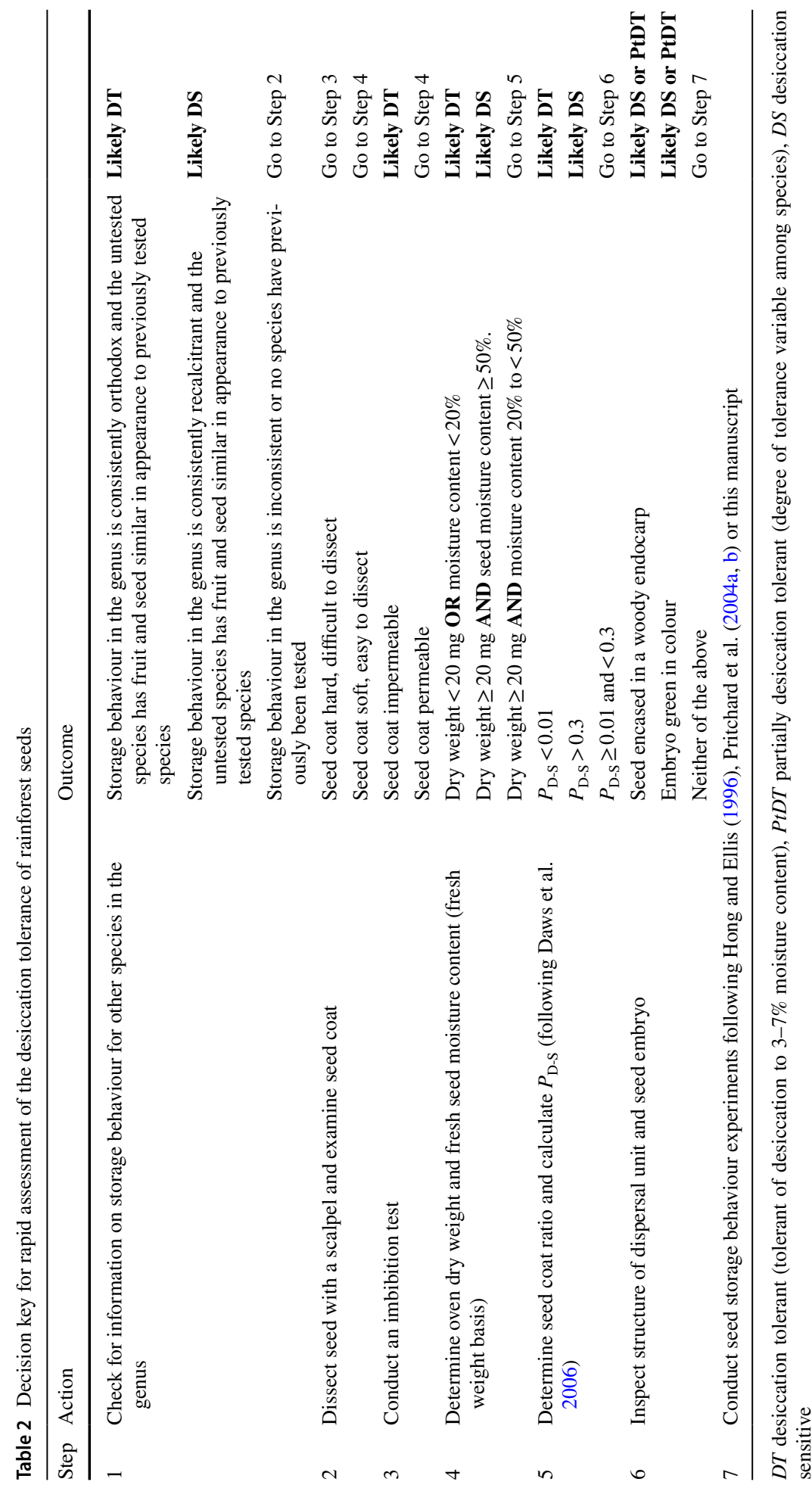


However, for the genera Ceratopetalum, Diospyros, Cryptocarya and Alphitonia, there were no easily discernible differences in fruit or seed structure that reflected differing responses to desiccation. The four species in Diospyros, for example, ranged from desiccation tolerant to desiccation sensitive, though all four species produce fleshy fruits and seeds with a similar structure. Likewise, in the Cryptocarya genus, the three species tested ranged from desiccation sensitive to partially desiccation tolerant though all three produced seeds with a thin seed coat surrounded by a woody endocarp. These results suggest that genus is best used as a predictor for storage response of an untested species when several species with similar seed structure in that genus have been tested and have shown a consistent response.

The comparatively low proportion of desiccation sensitive species found in this study (22\%) suggests that many of the seed-producing rainforest species in temperate and subtropical zones in Australia may potentially be conserved by some form of seed banking. Earlier studies of rainforest flora that have focussed on woody species found the proportion of desiccation sensitive species to be considerably higher (Daws et al. 2005; Hamilton et al. 2013; Lan et al. 2014). However, modelling by Wyse and Dickie (2017) predicted the proportion of desiccation sensitivity for subtropical to tropical moist broadleaf forest to be $18.5 \%$ if herbaceous species were included, a value much closer to that observed in this study. Given the great number of species occurring in these habitats (Sommerville et al. 2018), this represents the potential to conserve a significant amount of the world's rainforest flora. The high proportion of rainforest trees showing desiccation sensitivity, however, is a concern as a wide diversity of tree species - and the habitats they create-is a distinguishing feature of subtropical and tropical rainforests (Keppel et al. 2010; Tng et al. 2016; Ibanez et al. 2017).

Wyse and Dickie (2017) also found that seeds of up to $92 \%$ of the world's plant species may be stored using conventional methods. In the model used, however, desiccation tolerant and intermediate species were combined for the analysis on the basis of Tweddle et al.'s (2003) comment that intermediate seeds may be considered effectively desiccation tolerant in ecology, and on the basis that the limited number of intermediate species in the dataset had little impact on the outcome. While we adopted the same approach here when comparing characteristics of desiccation sensitive and desiccation tolerant seeds from Australia, China and Panama (17 partially desiccation tolerant seeds were included in the desiccation tolerant subset), we note that seeds with intermediate storage behaviour are not usually amenable to conventional seed banking (i.e. desiccation to 3-7\% moisture content and storage at -18 to $-20{ }^{\circ} \mathrm{C}$ ). The proportion of intermediate species available for modelling is likely to increase as more data from moist tropical-subtropical habitats becomes available, particularly from island habitats where dispersal over long distances may have selected against desiccation sensitive species.

Research on the native flora of Hawaii, for example, indicated that only $3 \%$ of species tested were truly desiccation sensitive (Yoshinaga and Walters 2003) and many species tolerant of desiccation have since been found to be 'temperature-intermediate', i.e. sensitive to storage at $-18{ }^{\circ} \mathrm{C}$ (Chau et al. 2019). Similarly, of the 105 desiccation tolerant species tested for freezing response in this study, $26 \%$ were found to be either freezing sensitive or short-lived in storage at -18 to $-20{ }^{\circ} \mathrm{C}$. These results suggest that standard seed banking temperatures may not be appropriate for seeds from rainforest habitat. Chau et al. (2019) came to a similar conclusion following paired studies of Hawaiian seeds stored at $5{ }^{\circ} \mathrm{C}$ and $-18{ }^{\circ} \mathrm{C}$ in which they found species from ten genera had greater longevity in storage at $5{ }^{\circ} \mathrm{C}$ than at $-18{ }^{\circ} \mathrm{C}$. An investigation of more appropriate storage temperatures is now needed for the Australian species found to be sensitive to freezing, and further testing 
is required to determine whether any species initially appearing tolerant of freezing after 1-2 months are in fact short-lived at that temperature.

The above results, combined with knowledge of an increasing number of orthodox species now known to be short-lived in storage (e.g. Mondoni et al. 2011; Merritt et al. 2014; Satyanti et al. 2018), suggest that the global proportion of angiosperms suitable for longterm conservation at -18 to $-20{ }^{\circ} \mathrm{C}$ may be somewhat lower than previously predicted. Urgent work is now required to identify other species that are likely to be short-lived at standard seed banking temperatures and to determine the storage conditions necessary to maximise their longevity. An assessment of thermal profiles using differential scanning calorimetry may aid in both respects (Mira et al. 2019).

A limitation of the present study is that, for most species, only a single accession was tested. Differences in response to drying and storage can occur among collections of a species from different provenances and among collections from different years (Dalziell et al. 2019). These differences in response can be influenced by the relative maturity of the seed at the time of collection (Hay and Smith 2003) and the quality of the seed as a result of maternal environment and genetic make-up (Delouche 1980; Roach and Wulff 1987). However, the desiccation response was consistent for eight species common to this study and that of Hamilton et al. (2013) suggesting that the majority of observations in this study are likely to be repeatable.

Relatively poor germination of fresh seeds of 151 species prevented a direct assessment of their storage behaviour. The poor response may have been due to inappropriate conditions for germination; however, poor, slow and erratic germination of rainforest seeds has been observed previously under laboratory conditions (Mattana et al. 2019), in nursery situations (Floyd 2008; Zich et al. 2018) and in field experiments (Doust et al. 2006). In fact, Baskin and Baskin (2014) reported that $51 \%$ of more than 6700 non-pioneer tree species in tropical-subtropical evergreen rainforests had some form of dormancy. This difficulty points to the need for research into dormancy and optimum germination conditions for rainforest species while supporting the need for methods to distinguish between bankable and non-bankable seeds without germination testing.

The data and the key presented here provide a step forward for those attempting to conserve rainforest species through seed banking in Australia and in other countries with rainforest habitats. Both the data and the key may also prove useful to those studying rainforest ecology and restoration, as the identification of desiccation response can: (a) provide an explanation for the failure of some species to re-establish naturally from seed in secondary rainforests or restoration sites (Goosem et al. 2016); (b) provide a guide to seeds that it may be better to bury when direct sowing, rather than broadcast, to prevent desiccation (see Doust et al. 2006); and (c) provide an indication of the time that may be required for emergence of seeds that are desiccation tolerant but dormant (Online Resource 1). While we expect that the key may need to be refined as more data comes to hand, this first iteration has significantly increased the speed with which storage behaviour may be assessed for a wide range of rainforest species.

Supplementary Information The online version contains supplementary material available at https://doi. org/10.1007/s10531-021-02244-1.

Acknowledgements We thank the sponsors of the Rainforest Seed Conservation Project-the Arcadia

Fund, the Greatorex Foundation, the Maxwell Foundation, HSBC Bank and several private benefactors-for funding the work of G Errington, G Liyanage, Z-J Newby and KD Sommerville. We thank Carmen Laidlaw, Harrison Palmer and Veronica Viler for assistance with germination testing, Richard 
Johnstone and Gavin Philips for assistance with seed collection, and two reviewers for suggestions that improved the manuscript.

Author contributions All authors contributed to the design and execution of storage experiments. KD Sommerville performed the data collation and analysis and wrote the first draft of the manuscript. All authors commented on previous versions of the manuscript and approved the final version.

Funding This research was funded by the Royal Botanic Gardens and Domain Trust, the Arcadia Fund, the Greatorex Foundation, the Maxwell Foundation, HSBC Bank and several private benefactors.

Data availability All data relating to germination and storage experiments are summarised in the supplementary material accompanying this manuscript. Raw data can be made available on request.

\section{Declarations}

Conflict of interest The authors declare no conflicts of interest or competing interests.

Open Access This article is licensed under a Creative Commons Attribution 4.0 International License, which permits use, sharing, adaptation, distribution and reproduction in any medium or format, as long as you give appropriate credit to the original author(s) and the source, provide a link to the Creative Commons licence, and indicate if changes were made. The images or other third party material in this article are included in the article's Creative Commons licence, unless indicated otherwise in a credit line to the material. If material is not included in the article's Creative Commons licence and your intended use is not permitted by statutory regulation or exceeds the permitted use, you will need to obtain permission directly from the copyright holder. To view a copy of this licence, visit http://creativecommons.org/licenses/by/4.0/.

\section{References}

Alamgir M, Turton SM, Macgregor CJ, Pert PL (2016) Assessing regulating and provisioning ecosystem services in a contrasting tropical forest landscape. Ecol Ind 64:319-334. https://doi.org/10.1016/j. ecolind.2016.01.016

Amigo I (2020) The Amazon's fragile future. Nature 578:505-507

Baskin CC, Baskin JM (2014) Seeds: ecology, biogeography and evolution or dormancy and germination, 2nd edn. Academic Press, San Diego

Berjak P, Pammenter NW (2008) From Avicennia to Zizania: seed recalcitrance in perspective. Ann Bot 101:213-228. https://doi.org/10.1093/aob/mcm168

Brandt P, Abson DJ, DellaSala DA, Feller R, von Wehrden H (2014) Multifunctionality and biodiversity: ecosystem services in temperate rainforests of the Pacific Northwest, USA. Biol Conserv 169:362371. https://doi.org/10.1016/j.biocon.2013.12.003

Campbell I (2007) Chi-squared and Fisher-Irwin tests of two-by-two tables with small sample recommendations. Stat Med 26:3661-3675. https://doi.org/10.1002/sim.2832

Chau MM, Chambers T, Weisenberger L, Keir M, Kroessig TI, Wolkis D, Kam R, Yoshinaga AY (2019) Seed freeze sensitivity and ex situ longevity of 295 species in the native Hawaiian flora. Am J Bot 106:1-23. https://doi.org/10.1002/ajb2.1351

Chen S-C, Wu L-M, Wang B, Dickie JB (2020) Macroevolutionary patterns in seed component mass and different evolutionary trajectories across seed desiccation responses. New Phytol 228:770-777. https://doi.org/10.1111/nph.16706

Corlett RT, Primack RB (2008) Tropical rainforest conservation: a global perspective. In: Carson W, Schnitzer S (eds) Tropical forest community ecology. Wiley, Chichester, pp 442-456

Costion CM, Simpson L, Pert PL, Carlson MM, Kress WJ, Crayn D (2015) Will tropical mountaintop plant species survive climate change? Identifying key knowledge gaps using species distribution modelling in Australia. Biol Conserv 191:322-330. https://doi.org/10.1016/j.biocon.2015.07.022

Craven LA, Biffen E (2005) Anetholea anisata transferred to, and two new Australian taxa of, Syzygium (Myrtaceae). Blumea 50:157-162. https://doi.org/10.3767/000651905X623346 
Dalziell EL, Funnekotter B, Mancero RL, Merritt DJ (2019) Seed storage behaviour of tropical members of the aquatic basal angiosperm genus Nymphaea L. (Nymphaeaceae). Conserv Physiol 7:1-15. https://doi.org/10.1093/conphys/coz021

Daws MI, Garwood NC, Pritchard HW (2005) Traits of recalcitrant seeds in a semi-deciduous tropical forest in Panama: some ecological implications. Funct Ecol 19:874-885. https://doi.org/10.1111/j. 1365-2435.2005.01034.x

Daws MI, Garwood NC, Pritchard HW (2006) Prediction of desiccation sensitivity in seeds of woody species: a probabilistic model based on two seed traits and 104 species. Ann Bot-London 97:667674. https://doi.org/10.1093/aob/mcl022

de Lima M Jr, Hong TD, Arruda YMBC, Mendes AMS, Ellis RH (2014) Classification of seed storage behaviour of 67 Amazonian tree species. Seed Sci Technol 42:363-392. https://doi.org/10.15258/ sst.2014.42.3.06

Delgado-Aguilar MJ, Konold W, Schmitt CB (2017) Community mapping of ecosystem services in tropical rainforest of Ecuador. Ecol Ind 73:460-471. https://doi.org/10.1016/j.ecolind.2016.10.020

Delouche JC (1980) Environmental effects on seed development and seed quality. HortSci 15:13-18

Dickie JB, Pritchard HW (2002) Systematic and evolutionary aspects of desiccation tolerance in seeds. In: Black M, Pritchard HW (eds) Desiccation and survival in plants: drying without dying. CABI Publishing, Wallingford, pp 239-259

Doust SJ, Erskine PD, Lamb D (2006) Direct seeding to restore rainforest species: microsite effects on the early establishment and growth of rainforest tree seedlings on degraded land in the wet tropics of Australia. Forest Ecol Manag 234:333-343. https://doi.org/10.1016/j.foreco.2006.07.014

Ellis RH, Mai-Hong T, Hong TD, Tan TT, Xuan-Chuong ND, Hung LQ, Ngoc-Tam B, Le-Tam VT (2007) Comparative analysis by protocol and key of seed storage behaviour of sixty Vietnamese tree species. Seed Sci Technol 35:460-476

FAO (2015) Global forest resources assessment. Food and Agriculture Organisation of the United Nations, Rome

Fensham RJ, Carnegie AJ, Laffineur B, Makinson RO, Pegg GS, Wills J (2020) Imminent extinction of Australian Myrtaceae by fungal disease. Trends Ecol Evol 35:554-557. https://doi.org/10.1016/j.tree.2020.03.012

Floyd AG (1990) Australian rainforests in New South Wales, vol 2. Surrey Beatty \& Sons, Chipping Norton

Floyd AG (2008) Rainforest trees of mainland south-eastern Australia, 2nd edn. Terania Rainforest Publishing, Lismore

Golden CD, Rasolofoniaina BJR, Anjaranirina EJG, Nicolas L, Ravaoliny L, Kremen C (2012) Rainforest pharmacopeia in Madagascar provides high value for current local and prospective global uses. PLoS ONE 7:e41221. https://doi.org/10.1371/journal.pone.0041221

Goosem M, Paz C, Fensham R, Preece N, Goosem S, Laurance S (2016) Forest age and isolation affect the rate of recovery of plant species diversity and community composition in secondary rain forests in tropical Australia. J Veg Sci 27:504-514. https://doi.org/10.1111/jvs.12376

Grubb PJ, Burslem DFRP (1998) Mineral nutrient concentrations as a function of seed size within seed crops: implications for competition among seedlings and defence against herbivory. J Trop Ecol 14:177-185. https://doi.org/10.1017/S0266467498000145

Halofsky JE, Peterson DL, Harvey BJ (2020) Changing wildfire, changing forests: the effects of climate change on fire regimes and vegetation in the Pacific Northwest, USA. Fire Ecol 16:4. https://doi.org/10.1186/ s42408-019-0062-8

Hamilton KN, Offord CA, Cuneo P, Deseo M (2013) A comparative study of seed morphology in relation to desiccation tolerance and other physiological responses in 71 Eastern Australian rainforest species. Plant Species Biol 28:51-62. https://doi.org/10.1111/j.1442-1984.2011.00353.x

Harden GJ, McDonald WJF, Williams JB (2006) Rainforest trees and shrubs: a field guide to their identification. Gwen Harden Publishing, Nambucca Heads

Harden GJ, McDonald WJF, Williams JB (2007) Rainforest climbing plants: a field guide to their identification. Gwen Harden Publishing, Nambucca Heads

Hay F, Smith RD (2003) Seed maturity: when to collect seeds from wild plants. In: Smith RD, Dickie JB, Linington SH, Pritchard HW, Probert R (eds) Seed conservation. Turning science into practice. Royal Botanic Gardens, Kew, pp 97-133

Hong TD, Ellis RH (1996) A protocol to determine seed storage behaviour. IPGRI Technical Bulletin No. 1. International Plant Genetic Resources Institute, Rome

Ibanez T, Chave J, Barrabé L, Elodie B, Boutreux T, Trueba S, Vandrot H, Birnbaum P (2017) Community variation in wood density along a bioclimatic gradient on a hyper-diverse tropical island. J Veg Sci 28:19-33. https://doi.org/10.1111/jvs. 12456

ISTA (2007) International Rules for Seed Testing. International Seed Testing Association, Bassersdorf 
Jayasuriya KMGG, Baskin JM, Baskin CC, Fernando MTR (2012) Variation in seed dormancy and storage behaviour of three liana species of Derris (Fabaceae, Faboideae) in Sri Lanka and ecological implications. Res J Seed Sci 5:1-18. https://doi.org/10.3923/rjss.2012.1.18

Keppel G, Buckley YM, Possingham HP (2010) Drivers of lowland rain forest community assembly, species diversity and forest structure on islands in the tropical South Pacific. J Ecol 98:87-95. https://doi.org/10. 1111/j.1365-2745.2009.01595.x

Kruskal WH, Wallis WA (1952) Use of ranks in one-criterion variance analysis. J Am Stat Assoc 47:583-621. https://doi.org/10.2307/2280779

Lan Q, Xia K, Wang X, Liu J, Zhao J, Tan Y (2014) Seed storage behaviour of 101 woody species from the tropical rainforest of southern China: a test of the seed-coat ratio-seed mass (SCR-SM) model for determination of desiccation sensitivity. Aust J Bot 62:305-311. https://doi.org/10.1071/BT14037

Liu U, Breman E, Cossu TA, Kenney S (2018) The conservation value of germplasm stored at the Millennium Seed Bank, Royal Botanic Gardens, Kew, UK. Biodivers Conserv 27:1347-1386. https://doi.org/10.1007/ s10531-018-1497-y

Makinson RO (2018) Myrtle rust reviewed: the impacts of the invasive plant pathogen Austropuccinia psidii on the Australian environment. (Plant Biosecurity Cooperative Research Centre: Canberra). https://www. anpc.asn.au/myrtle-rust/. Accessed 13 June 2019

Mattana E, Peguero B, Di Sacco A, Agramonte W, Castillo WRE, Jiménez F, Clase T, Pritchard HW, GómezBarreiro P, Castillo-Lorenzo E, Encarnación MT, Way MJ, García R, Ulian T (2019) Assessing seed desiccation responses of native trees in the Caribbean. New For 51:705-721. https://doi.org/10.1007/ s11056-019-09753-6

Mira S, Nadarajan J, Liu E, Gonzalez-Benito ME, Pritchard HW (2019) Lipid thermal fingerprints of long-term stored seeds of Brassicaceae. Plants 8:414. https://doi.org/10.3390/plants8100414

Merritt DJ, Martyn AJ, Ainsley P, Young RE, Seed LU, Thorpe M, Hay FR, Commander LE, Shackelford N, Offord CA, Dixon KW, Probert RJ (2014) A continental-scale study of seed lifespan in experimental storage examining seed, plant, and environmental traits associated with longevity. Biodivers Conserv 23:1081-1104. https://doi.org/10.1007/s10531-014-0641-6

Mondoni A, Probert RJ, Rossi G, Vegini E, Hay FR (2011) Seeds of alpine plants are short-lived: implications for long-term conservation. Ann Bot 107:171-179. https://doi.org/10.1093/aob/mcq222

Nahuelhual L, Donoso P, Lara A, Núñez D, Oyarzún C, Neira E (2007) Valuing ecosystem services of Chilean temperate rainforests. Environ, Dev Sustain 9:481-499. https://doi.org/10.1007/s10668-006-9033-8

NSW DPIE (2020) NSW Fire and the Environment 2019-20 Summary. New South Wales Department of Planning, Industry and Environment, Sydney

Offord CA, Meagher PF (2009) Plant germplasm conservation in Australia: strategies and guidelines for developing, managing and utilising ex situ collections. Australian Network for Plant Conservation, Canberra

Pelissari F, José AC, Fontes MAL, Matos ACB, Pereira WVS, Faria JMR (2018) A probabilistic model for tropical tree seed desiccation tolerance and storage classification. New For 49:143-158. https://doi.org/10. 1007/s11056-017-9610-8

Pritchard HW, Daws MI, Fletcher BJ, Gaméné CS, Msanga HP, Omondi W (2004a) Ecological correlates of seed desiccation tolerance in tropical African dryland trees. Am J Bot 91:863-870. https://doi.org/10. 3732/ajb.91.6.863

Pritchard HW, Wood CB, Hodges SS, Vautier HJ (2004b) 100-seed test for desiccation tolerance and germination: a case study on eight tropical palm species. Seed Sci Technol 32:393-403. https://doi.org/10.15258/ sst.2004.32.2.11

RBG\&DT (2020) PlantNET: the NSW plant information network system. Royal Botanic Gardens and Domain Trust, Sydney

Roach DA, Wulff RD (1987) Maternal effects in plants. Ann Rev Ecol Syst 18:209-235. https://doi.org/10. 1146/annurev.es.18.110187.001233

Roberts EH (1973) Predicting the storage life of seeds. Seed Sci Technol 1:499-514

Royal Botanic Gardens Kew (2020) Seed information database (SID), version 7.1. Royal Botanic Gardens, Kew

Satyanti A, Nicotra AB, Merkling T, Guja LK (2018) Seed mass and elevation explain variation in seed longevity in Australian alpine species. Seed Sci Res 28:319-331. https://doi.org/10.1017/S0960258518000090

Sommerville KD, Clarke B, Keppel G, McGill C, Newby Z, Wyse SV, James SA, Offord CA (2018) Saving rainforests in the South Pacific: challenges in ex situ conservation. Aust J Bot 65:609-624. https://doi.org/ 10.1071/BT17096

Sommerville KD, Cuneo P, Errington G, Makinson RO, Pederson S, Phillips G, Rollason A, Viler V, Offord CA (2019) Conservation in the wake of myrtle rust-a case study on two critically endangered Australian rainforest plants. Pacific Conserv Biol 26:218-229. https://doi.org/10.1071/PC19026

Tng DYP, Apgaua DMG et al (2016) Vegetation and floristics of a lowland tropical rainforest in northeast Australia. Biodivers Data J 4:e7599. https://doi.org/10.3897/BDJ.4.e7599 
Tweddle JC, Dickie JB, Baskin CC, Baskin JM (2003) Ecological aspects of seed desiccation sensitivity. J Ecol 91:294-304. https://doi.org/10.1046/j.1365-2745.2003.00760.x

Vázquez-Yanes C, Orozco-Segovia A (1993) Patterns of seed longevity and germination in the tropical rainforest. Annu Rev Ecol Syst 24:69-87. https://doi.org/10.1146/annurev.es.24.110193.000441

Wyse SV, Dickie JB (2017) Predicting the global incidence of seed desiccation sensitivity. J Ecol 105:10821093. https://doi.org/10.1111/1365-2745.12725

Wyse SV, Dickie JB (2018) Taxanomic affinity, habitat \& seed mass predict desiccation response. Ann BotLondon 121:71-83. https://doi.org/10.1093/aob/mcx128

Xu T, Hutchison M (2010) ANUCLIM version 6.1 User Guide. Australian National University, Canberra

Xu T, Kesteven J, Hutchison M (2014a) Daily maximum temperature: ANUClimate 1.1, 0.01 degree, Australian Coverage, 1970-2014. Australian National University, Canberra

Xu T, Kesteven J, Hutchison M (2014b) Daily minimum temperature: ANUClimate 1.1, 0.01 degree, Australian Coverage, 1970-2014. Australian National University, Canberra

Xu T, Kesteven J, Hutchison M (2014c) Daily total precipitation: ANUClimate 1.0, 0.01 degree, Australian Coverage, 1970-2014. Australian National University, Canberra

Yoshinaga AY, Walters C (2003) Conservation of tropical seeds: an example from Hawai'i. In: Smith RD, Dickie JB, Linington SH, Pritchard HW, Probert RJ (eds) Seed conservation: turning science into practice. The Royal Botanic Gardens, Kew, pp 956-963

Zich FA, Hyland BPM, Whiffin T, Kerrigan RA (2018) Australian Tropical Rainforest Plants, $7^{\text {th }}$ edition. http:// www.canbr.gov.au/cpbr/cd-keys/RFK7/key/RFK7/Media/Html/entities/index.htm. Accessed 21 Sept 2020

Publisher's Note Springer Nature remains neutral with regard to jurisdictional claims in published maps and institutional affiliations. 